\title{
Higher-Order Organization by Mesoscale Self-Assembly and Transformation of Hybrid Nanostructures
}

Helmut Cölfen and Stephen Mann*

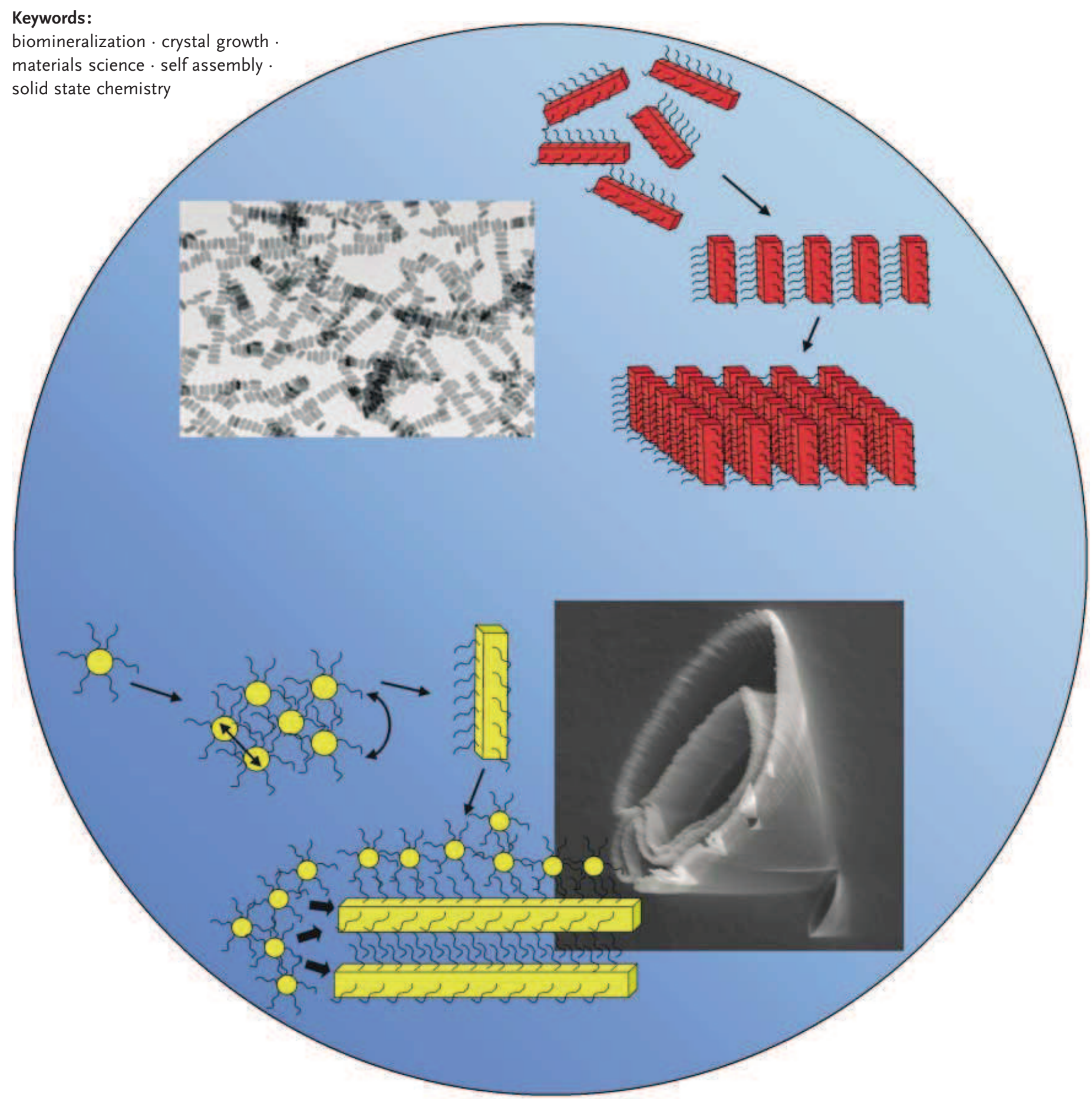



such as patterning, rather than the spontaneous chemical assembly and transformation of building blocks across multiple length scales. It should be possible to develop a chemistry of organized matter based on emergent processes in which time- and scale-dependent coupling of interactive components generate higher-order architectures with embedded structure. Herein we highlight how the interplay between aggregation and crystallization can give rise to mesoscale selfassembly and cooperative transformation and reorganization of hybrid inorganic-organic building blocks to produce single-crystal mosaics, nanoparticle arrays, and emergent nanostructures with complex form and hierarchy. We propose that similar mesoscale processes are also relevant to models of matrix-mediated nucleation in biomineralization.

\section{From the Contents}

\begin{tabular}{l} 
1. Introduction \\
$\begin{array}{l}\text { 2. Kinetic Control of Nucleation } \\
\text { and Growth }\end{array}$ \\
$\begin{array}{l}\text { 3. Aggregation-Mediated } \\
\text { Pathways of Crystal Growth }\end{array}$ \\
$\begin{array}{l}\text { 4. Mesoscale Self-Assembly of } \\
\text { Nanoparticle Arrays }\end{array}$ \\
$\begin{array}{l}\text { 5. Mesoscale Transformations and } \\
\text { Emergent Nanostructures }\end{array}$ \\
$\begin{array}{l}\text { 6. Mesoscale Transformations and } \\
\text { Matrix-Mediated Nucleation in } \\
\text { Biomineralization }\end{array}$ \\
\hline $\begin{array}{l}\text { 7. Summary and Outlook } \\
2367\end{array}$
\end{tabular}

\section{Introduction}

It is self evident that the organization and transformation of matter and energy are fundamental aspects of the universe. How these processes occur and the nature of the properties they encode are quintessential questions for all scientific disciplines past and present. In this regard, chemistry occupies the middle ground between physics and biology as it deals with the ordering and rearrangement of atoms at the molecular level, rather than the fundamental subatomic nature of matter or its animation in macroscopic time dependent structures. Nanochemistry aims to extend the traditional length scales of synthetic chemistry and exploit the collective properties of organized assemblies produced by processes, such as, controlled crystallization and supramolec ular complementarity. Although many approaches seek to mimic the information processing and sensing capabilities of biological nanostructures, they often lack the inherent materials building properties typical of organisms, which are essential if nanostructures are to be organized across many length scales and used as functional materials within inte grated systems. For this reason, strategies have been devel oped for the long range organization and assembly of nano structured phases. For example, chemical and microfabrica tion methods can be combined to produce externally pat terned materials, ${ }^{[1,2]}$ whereas spontaneous processes associ ated with solvent evaporation, ${ }^{[3,4]}$ molecular cross linking, ${ }^{[5,6]}$ or programmed recognition ${ }^{[7}$ 9] have been used to control the deposition of nanoparticle based superlattices. Although promising, these approaches have disadvantages associated with the sequential processing and the physical fabrication, as well as limitations arising from the restricted number of superlattices available because of thermodynamic (packing) constraints on self assembly. Indeed, structural organization in many of these systems depends on physics and crystal engineering rather than chemistry.
On the other hand, it should be possible to develop a chemistry of organized matter that couples together synthesis and self assembly to produce, in situ, complex higher order structures. In such cases, the embedding of structures over multiple length scales will arise as an emergent property that is not directly related to the smallest building blocks but is dependent on how these units evolve in time and space. Thus, different driving forces will operate at various stages along the synthesis construction pathway such that these forces become superimposed mechanistically. For example, whereas localized molecular interactions can dominate ordering transitions on the nanoscale, surface forces are important in determining how nanostructures become assembled at the mesoscopic level. And beyond the colloidal regime, mechan ical forces, such as internal strain, can drive transformations that result in macroscopic order.

It seems unlikely that significant levels of complexity can emerge for single component systems as the scope for switch ing between these different length scale dependent regimes is severely limited by homogeneity. But increasing the number of interactive components should significantly enhance the diversity of emergent structures, particularly when inorganic and organic building blocks are present because of the

[*] Prof. S. Mann

School of Chemistry

University of Bristol

Bristol BS8 1TS (UK)

Fax: (+44) 1179290509

Email:s.mann@bristol.ac.uk

Dr. H. Cölfen

Max Planck Institut für Kolloid und Grenzflächenforschung, Kol loidchemie

Forschungscampus Golm, 14424 Potsdam (Germany) 
resulting disparate driving forces. In such circumstances, there needs to be a balance between the forces responsible for the self organization of individual components and those required for mutual coassembly. If the former are predom inant, then phase separated structures will be synthesized, whereas domination of the latter can result in nonequilibrium conjugated architectures. This situation is exemplified by the hierarchical and hybrid nature of many biological minerals, which arise from an underlying synergy between the force fields of inorganic precipitation and biological organiza tion. ${ }^{[10]}$ Such materials illustrate the fundamental difference between notions of "organized" and "condensed" forms of matter, and have served as important archetypes in the biomimetic synthesis of higher order structures. ${ }^{[11,12]}$

Underpinning the synthesis of emergent structures are two general engines of construction that propagate and integrate structures from the molecular to macroscopic scales: crystallization and aggregation. Herein, we focus on the relationships between these processes in the presence of inorganic organic building blocks, particularly at the meso scale level where aggregation and crystallization can become intimately linked to generate hybrid single crystal mosaics (Section 3), coassembled nanoparticle arrays (Section 4), and embedded higher order nanostructures (Section 5).

Because the driving force for crystallization can be very strong and readily sustained, it is not so easily embedded within the construction process unless subject to kinetic regulation. We therefore begin our discussion with the general case of kinetic control in nucleation and growth, which highlights the importance of phase transformations in sequential processes involving amorphous precursors and crystalline intermediates (Section 2). A model of crystal growth based on aggregation mediated processes is then described and extended to consider the important influence of surface adsorbed macromolecules and surfactants on crystal texture and composition (Section 3 ). This approach leads to the mesoscale self assembly of inorganic organic hybrid nanoparticles, which we consider first in regard to stable (nontransformable) inorganic building blocks with either crystalline or amorphous structures linked by organic connectors (Section 4). In contrast, in Section 5 we discuss the more complex situation in which aggregates consisting of metastable inorganic organic building blocks undergo meso scale transformations. We show that amorphous to crystalline transformations of the inorganic phase can be strongly coupled with organic mesophase transitions to produce emergent hybrid nanostructures with complex shapes and hierarchical organization. Finally, we propose that mesoscale transformations involving cooperative reorganization of cou pled inorganic and organic components could be relevant in models of matrix mediated nucleation in biomineralization (Section 6).

\section{Kinetic Control of Nucleation and Growth}

One of the many distinguishing features of biominerals is that they are produced in heterogeneous environments at ambient temperature and pressure and $\mathrm{pH}$ values close to neutral. In comparison, materials synthesis usually demands harsh conditions, and even so called "soft chemical" methods may involve hydrothermal or solvothermal procedures and extreme $\mathrm{pH}$ values, or conditions, such as, microwave radia tion. ${ }^{[13,14]}$

Biological boundary conditions clearly limit the number and types of minerals that can be deposited from aqueous solutions but, on the other hand, increase the scope for controlled fabrication by shifting the reaction profile from themodynamic to kinetic driving forces. In general, kinetic control is based predominantly on the modification of the activation energy barriers of nucleation, growth, and phase transformation (Figure 1). In such cases, crystallization often proceeds by a sequential process involving structural and compositional modifications of amorphous precursors and crystalline intermediates, rather than a single step path way. ${ }^{[15,16]}$ How far these phase transformations proceed along a series of increasingly stable intermediates depends on the solubilities of the minerals and on the free energies of activation of their interconversions, all of which are strongly influenced by additives ${ }^{[10]}$ The corresponding changes in composition and structure usually occur by dissolution renu cleation processes closely associated with the surface and/or the interior of preformed particles. The nucleation of a particular crystalline phase is therefore highly heterogeneous and dependent on interfacial and hydrodynamic properties as well as reaction kinetics. Therefore, this process cannot be

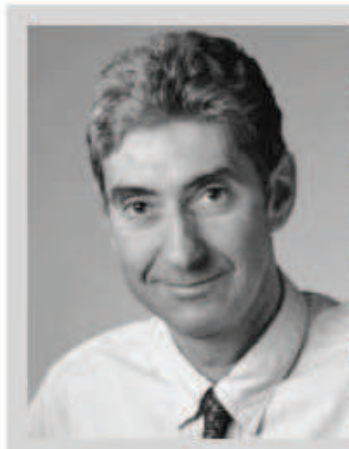

Stephen Mann is Professor in the School of Chemistry and Director of the Centre for Organized Matter Chemistry at the Univer sity of Bristol. He received his B.Sc. in chemistry from the University of Science and Technology in Manchester in 1976, and was awarded a D.Phil, in 1982 from the Univer sity of Oxford He took up a lectureship at the University of Bath in 1984 followed by a full professorship in 1990. He subsequently moved to his current position in 1998. He was admitted as a Fellow of the Royal Soci ety of Chemistry in 1996 and has obtained several awards including the Corday Morgan Medal (1993) and Interdisci plinary Award (1999) from the Royal Society of Chemistry, and Vinci Sci ence for Art Prize (1996).

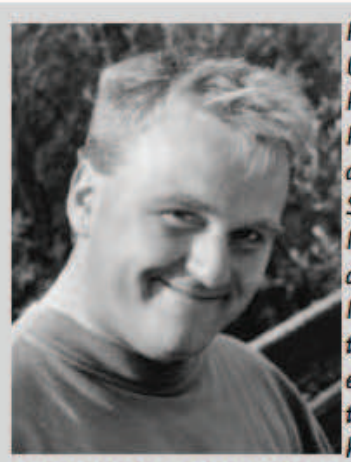

Helmut Colfen studied Chemistry at the University Duisburg and completed his Ph.D. in 1993 under the supenvision of Prof. Dr. Werner Borchard. After a Postdoc at the University of Nottingham, with Prof. Stephen Harding, in 1995 he joined the Max Planck Institute of Colloids and Interfa ces where he is a project leader in Prof. Markus Antonietti's group. After his habilita tion in 2001, he was employed as senior sci entist and head of the analytical service in the colloid chemistry department. Among his awards are the Hochschulabsolventen preis of the Gerhard Mercator University Duisburg and the Hermann Schnell award of the German Chemical Society (GDCh). 


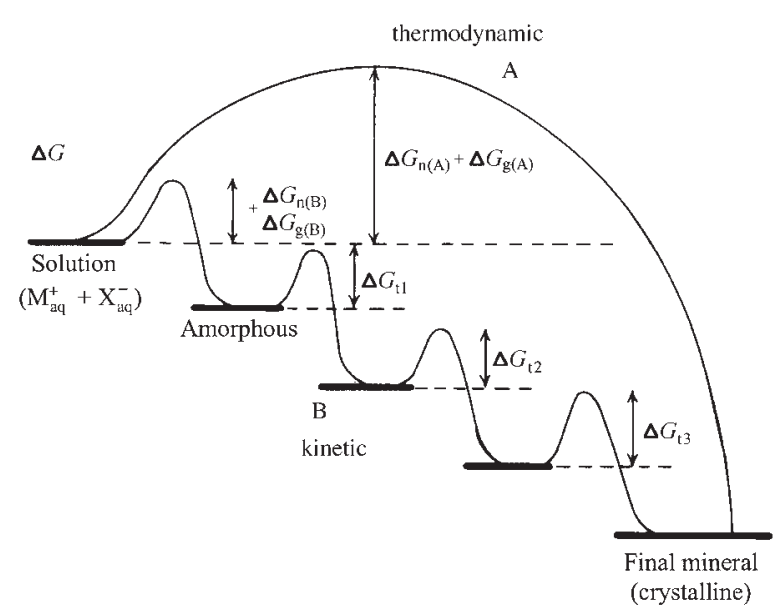

Figure 1. Crystallization pathways under thermodynamic and kinetic control. Whether a system follows a one step route to the final mineral phase (pathway A) or proceeds by sequential precipitation (pathway B), depends on the free energy of activation $(\Delta G)$ associated with nuclea tion $(\mathrm{n})$, growth $(\mathrm{g})$, and phase transformation $(\mathrm{t})$. Amorphous phases are common under kinetic conditions.

readily described by the classical model of nucleation, which is based on a thermodynamic treatment of the interplay between energy gain through bulk crystallization and energy loss through increase in surface area. ${ }^{[17]}$

Kinetically driven crystallization often involves an initial amorphous phase that may be nonstoichiometric, hydrated, and susceptible to rapid phase transformation. Amorphous calcium carbonate (ACC) for instance is highly soluble and rapidly transforms to calcite, vaterite, or aragonite unless kinetically stabilized. In biomineralization, this stabilization is achieved by ions such as $\mathrm{Mg}^{2+}$ and $\mathrm{PO}_{4}{ }^{3-}$, or by enclosing the amorphous phase in an impermeable sheath of organic macromolecules, such as polysaccharides ${ }^{[18]}$ or mixtures of polysaccharides and proteins rich in glutamic acid, threonine, and serine. ${ }^{[19,20]}$ Thus a significant number of stabilized ACC biominerals has now been documented in plant cystoliths, ${ }^{[21,22]}$ snail shells, ${ }^{[23]}$ ascidian spicules, ${ }^{[19,24]}$ and crustacean exoskel etons. ${ }^{[25]}$ In contrast, controlled phase transformation of ACC results in the deposition of calcite spicules in sea urchin larvae. ${ }^{[26,27]}$ Interestingly, many biogenic calcites contain high levels (up to $30 \mathrm{~mol} \%$ ) of $\mathrm{Mg}^{2+}$ ions in the crystal lattice, and one possibility is that such high isomorphic substitution contents originate from associated $\mathrm{Mg}$ rich ACC precursors. Although confirmation of these biogenic precursors has not yet been reported, laboratory experiments on calcite crystal lization from supersaturated solutions containing a 4:1 $\mathrm{Mg}^{2+}: \mathrm{Ca}^{2+}$ molar ratio in the absence or presence of polyasparate, polyacrylate, or macromolecules extracted from the high $\mathrm{Mg}$ calcite skeleton of a coralline alga showed in each case that ACC phase transformation resulted in calcite crystals with $\mathrm{Mg}$ levels of approximately $20 \mathrm{~mol} \% .^{[24]}$ This level is significantly greater than the $10 \mathrm{~mol} \%$ found in the thermodynamically stable $\mathrm{Mg}$ calcite, and indeed such high substitution levels are unlikely to be attained under ambient conditions by a single step crystal lization process because the concomitant amounts of soluble
$\mathrm{Mg}^{2+}$ ions required result in the kinetic precipitation of aragonite.

Kinetic control of crystallization can be achieved by modifying the interactions of nuclei and developing crystals with solid surfaces and soluble molecules. ${ }^{[28]}$ Such processes influence the structure and composition of the nuclei, particle size, texture, habit and aggregation, and stability of inter mediate phases. In biomineralization, for example, structured organic surfaces are considered to play a key role in organic matrix mediated deposition by lowering the activation energy of nucleation of specific crystal faces and polymorphs through interfacial recognition (see Section 6 for further details). ${ }^{[29]}$ Soluble macromolecules and organic anions, as well as inorganic ions, such as $\mathrm{Mg}^{2+}$ and $\mathrm{PO}_{4}{ }^{3-}$, can also have a marked kinetic effect on crystallization, particularly with regard to polymorph selectivity and habit modification. These interactions can be highly specific; for example, proteins extracted either from calcite or aragonite containing layers of the abalone shell induce the crystallization of calcite or aragonite, respectively, when added to supersaturated sol utions of calcium hydrogen carbonate in the laboratory. ${ }^{[30]}$ Atomic force microscope (AFM) studies ${ }^{[31]}$ indicate that the macromolecules bind to growth sites on well defined crystal surfaces and influence the kinetics of crystal growth from solution in accordance with the classical model of secondary nucleation. ${ }^{[32]}$ Although there is much experimental evidence to support these molecular based mechanisms, the studies usually concern macroscopic crystals with well established faces and edges, so information about the early stages of growth at the colloidal level are not generally available. Significantly, as discussed in Section 3, recent studies indicate that aggregation of primary particles can be an important mechanism of crystallization at the mesoscopic length scale, particularly in kinetically controlled systems. The influence of macromolecules on this process has not been generally considered.

We now discuss aggregation induced crystallization and extend this mechanism to inorganic organic hybrid building blocks to highlight new insights into the design of synthesis routes to crystals with complex textures and morphologies, as well as organized assemblies of organically interconnected nanoparticles.

\section{Aggregation-Mediated Pathways of Crystal Growth}

The classical model of crystallization considers growth essentially as an amplification process in which stable nuclei are simply enlarged by unit cell replication without incurring structural changes in the bulk or at the surface. In contrast, crystal growth by aggregation of preformed crystalline build ing blocks is a mesoscale assembly process that results in single crystals with iso oriented mosaic textures (Figure 2). This process can occur through the coalescence of primary nanoparticles into colloidal aggregates, often of uniform size, and their subsequent internal restructuring to produce a crystallographically continuous particle. ${ }^{[33]}$ Alternatively, nanoparticles can become attached stepwise to a growing 


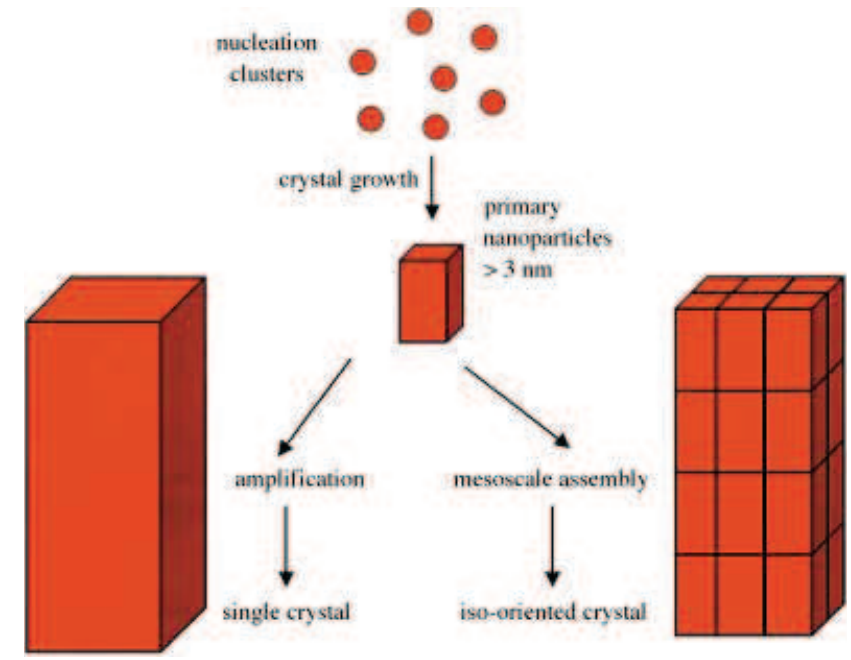

Figure 2. Alternative mechanisms of growth for single crystals.

assembly of aligned building blocks to produce, for example, chains of oriented nanocrystals. ${ }^{[34]}$

Aggregation mediated crystallization appears to be prom inent for solids, such as iron oxides, ${ }^{[35]}$ cerium oxide, ${ }^{[36]}$ copper oxalates, ${ }^{[33]}$ and copper oxides, ${ }^{[37]}$ which contain metal ions that readily undergo hydrolytic polymerization and cluster formation in aqueous solution. The resulting nanoparticles have surface charges that are highly sensitive to changes in $\mathrm{pH}$ value and ionic strength. Neutralization of surface species by the hydrolytic transformation of hydroxy $(\mathrm{OH})$ centers to oxo ( $\mathrm{O}$ ) bridges releases protons that can reduce the surface charge of dispersed nanoparticles to values equal to the isoelectric point, and thereby induce colloidal aggrega tion, which under appropriate conditions can occur concur rently with crystallization. For iron oxides, this generally requires hydrothermal aging of amorphous hydrated phases to produce well ordered nanocrystal superstructures, ${ }^{[38]}$ whereas copper oxides crystallize directly upon neutraliza tion induced metal ion hydrolysis. ${ }^{[37]}$ In such cases, primary nanocrystals are nucleated, which subsequently aggregate as the surface charge is progressively reduced by hydrolysis. Because the onset of aggregation is coupled temporally with crystallization, the size and shape of the primary particles, as well as the colloidal aggregates, are often highly homoge neous. This is particularly the case when the primary nano particles are produced by a single nucleation event such that the building blocks are effectively consumed during the aggregation process. ${ }^{[39]}$ For example, monodisperse $\mathrm{CuO}$ colloids, $300 \mathrm{~nm}$ in size, have been prepared from $20 \mathrm{~nm}$ sized $\mathrm{CuO}$ nanocrystals by self limiting aggregation. ${ }^{[37]}$ In contrast, if the rate of nucleation and growth of the nano crystals is constant throughout the aggregation process then the continuous supply of primary particles compensates for their consumption and polydispersity in aggregate size increases.

Transformation of nucleation clusters to stable crystalline building blocks will affect the structure, size, and shape of the primary particles, which in turn influence the mode of aggregation at the mesoscopic level. In particular, building blocks with high shape anisotropy, such as nanorods and nanodisks, will spontaneously align to produce crystals with analogous morphologies. Thus, changes in crystal habit can arise from modifications in the nanoscopic morphology of the building blocks, rather than by interactions between the crystal surfaces and environment as proposed in classical models of crystal growth. For example, variations in the morphology of colloidal hematite $\left(\alpha \mathrm{Fe}_{2} \mathrm{O}_{3}\right)$ have been attributed to differences in the shape of nanoparticle building blocks. ${ }^{[40]}$ Remarkably, even spherical primary particles can give rise to vectorial aggregation to produce ovoid or spindle shaped aggregates. ${ }^{[37]}$ This effect suggests that the interaction potential between the isometric building blocks is dependent on a multitude of factors, such as the actual combination of crystal faces expressed, electrostatic and dipolar fields associated with the aggregate, and hydrodynamic and van der Waals forces.

The controlled growth of a continuous single crystal from aggregated nanocrystals necessitates that the primary par ticles become aligned and interconnected along a common crystallographic axis. Studies have shown that crystallograph ically aligned chains of $\mathrm{TiO}_{2}$ nanoparticles are produced under hydrothermal conditions at near flocculation condi tions and close to the isoelectric point by oriented attachment of preformed nanocrystals. ${ }^{[34]} \mathrm{A}$ similar mechanism has been proposed for certain iron oxides ${ }^{[41]}$ and $\mathrm{ZnO}$ nanorods. ${ }^{[42]}$ In such cases, the nanocrystals are facetted and aligned by "docking" processes involving crystallographic fusion between certain high surface energy faces. Moreover, stresses associated with defects caused by initial mismatching at the particle particle interface might be sufficient to induce rotation of the crystallites into an aligned configuration. ${ }^{[43]}$ It seems possible that such processes could also occur within aggregates, along with coherent restructuring at the parti cle particle interfaces. ${ }^{[3,35,37,44]}$ The latter could involve densification, and intra aggregate reactivity and ripening. For example, in situ hydrolysis at the interfaces between adjacent metal oxide nanoparticles could increase the density and expel occluded solvent from the interior of the hydrated aggregates. A high level uniformity in the size and shape of the primary particles is expected to facilitate long range crystallographic coherence because of more efficient packing and epitaxial matching, provided that the interparticle forces resulting from the partial balancing of attractive van der Waals and repulsive electrostatic interactions are not so strong that the initial orientations are irreversibly fixed. Indeed, some degree of "error correction" must operate if the colloidal aggregates are to restructure into well ordered single crystals. In this regard, dynamic processes, such as jiggling of the nanoparticles within the aggregate by Brow nian motion ${ }^{[41]}$ or a modified Ostwald ripening process in which particles in crystallographic alignment are preferen tially stabilized whilst non aligned crystallites within the aggregates dissolve, ${ }^{[34]}$ could be of key importance. 


\subsection{Macromolecules and Crystal Textures}

It is evident from many studies that soluble macromole cules can influence crystal habit by selective adsorption processes that lead to preferential growth inhibition for distinct crystal faces, in analogy to the adsorption of low molar mass additives or inorganic ions. ${ }^{[45]}$ If such processes take place within a multistep growth mechanism, complex single crystal morphologies, such as $\mathrm{BaSO}_{4}$ flowerlike single crystalline particles with forbidden 10 fold symmetry, ${ }^{[46]}$ can be produced. In this case, the polymer additive interacts with primary $\mathrm{BaSO}_{4}$ nanocrystals indicating that soluble macro molecules and surfactants can have marked effects on the very early stages of crystal growth. Moreover, macromole cules are expected to be associated with aggregation based pathways of crystal growth for several reasons. It is well known that many polymers in solution can induce colloidal aggregation by enthalpic changes (surface binding and interparticle bridging), as well as nonadsorption entropic mechanisms (depletion flocculation). ${ }^{[47,48]}$ This process is the molecular basis for polymeric scale inhibition. In addition, strong attractive interactions with the inorganic surface can arrest nucleation and change the shape and size of the primary clusters. In this way stabilized nanocrystals with anchored organic ligands (Figure 3) are produced. Such particles are hybrids consisting of inorganic cores and organic shells, and can undergo controlled aggregation in aqueous solutions to produce textured single crystals. Steric, van der Waals and hydrophilic hydrophobic interactions involving the pendent chains of the adsorbed polymers or surfactants, as well as shape anisotropy, can influence the assembly of the primary particles. Moreover, modifications in crystal habit can arise from macromolecular induced changes in the shape of the aggregating crystal nuclei rather than solution based interactions at the particle surfaces. ${ }^{[33]}$

Strong binding interactions between the macromolecules and nanocrystals involved in aggregation mediated crystal growth will tend to produce crystals containing significant levels of occluded organic molecules, which unless desorbed or cleaved during restructuring will be included in the internal composition and texture. For example, copper oxalate crystals grown in the presence of hydroxypropyl methycellulose have a polymer content of $0.41 .5 \mathrm{wt} \% .{ }^{[33]}$ Likewise, levels of between $512 \mathrm{wt} \%$ and $430 \mathrm{wt} \%$ depending on the initial polymer concentration have been determined for $\mathrm{BaSO}_{4}{ }^{[49]}$ and $\mathrm{ZnO}^{[50]}$ crystals, respectively. Functionalized latexes can also be incorporated into growing single crystals. ${ }^{[51]}$ Inter calated macromolecules are common in many biominerals, such as the single crystal $\mathrm{Mg}$ calcite spines of the adult sea urchin that contain $0.02 \mathrm{wt} \%$ of protein, which is sufficient to modify their mechanical properties. ${ }^{[52]}$ These bio minerals, like their inorganic counterparts grown in the presence of polymers, are not only hybrid composites but exhibit modified domain struc tures. This situation is manifested in the corre sponding $\mathrm{X}$ ray diffraction patterns that show shortening of the coherence length and widening a)

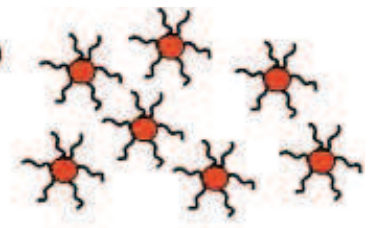

b)

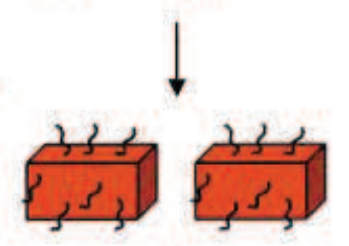

c)

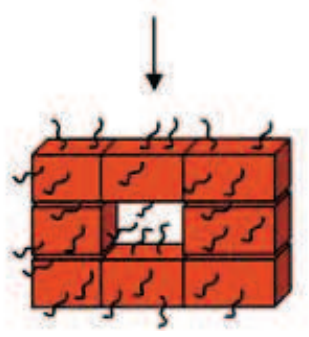

Figure 3. Influence of macromolecules and surfactants on crystalliza tion by aggregation mediated processes: a) spatially arrested nuclea tion of organic inorganic hybrid clusters, b) size and shape modified hybrid nanocrystals, and c) controlled aggregation and formation of iso oriented mosaic crystals with internal macromolecular rich domains.

of the angular spread associated with the mosaic struc ture. ${ }^{[33,53,54]}$

High concentrations of intercalated macromolecules will curtail restructuring within the nanocrystal aggregates with the consequence that crystallographic discontinuities will become prevalent as the hybrids increase in size. The corresponding changes in internal texture for $\mathrm{BaSO}_{4}$ and $\mathrm{CaCO}_{3}$ crystals have been revealed by thin sectioning and TEM analysis (Figure 4). ${ }^{[55,56]}$ In both cases, the single crystals consist of a central region of oriented primary particles with sizes in the order of several tens of nanometers that are interspaced with polymer rich domains. In contrast, the outer regions of the hybrid structure comprise considerably larger particles with a progressive increase in the angular spread. One possibility is that internal strain associated with defects
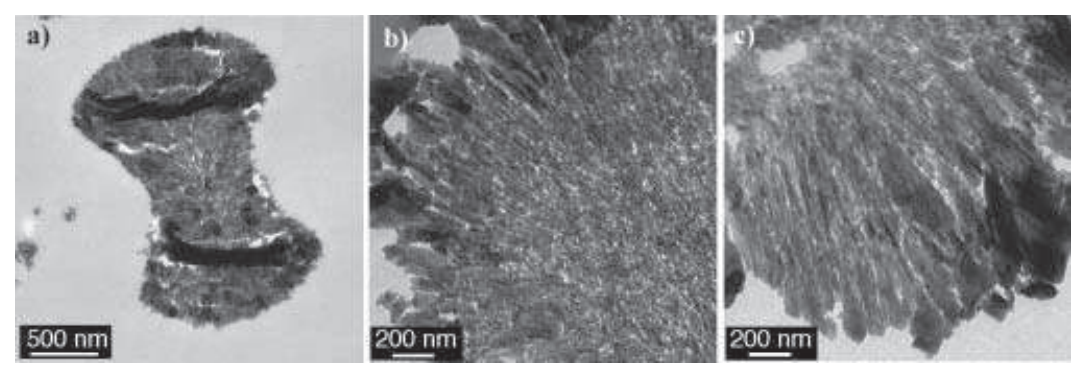

Figure 4. TEM micrographs of thin slices of dumbbell shaped crystals grown in the pres ence of double hydrophilic block copolymers showing oriented internal domain structure. a) $\mathrm{BaSO}_{4}$ crystal formed in the presence of $1 \mathrm{~g} \mathrm{~L}{ }^{1}$ poly (ethylene oxide) block poly(edta) at $\mathrm{pH} 5$ (edta ethylenediaminetetraacetic acid). ${ }^{[5]}$ b) and c) central and edge regions, respectively, of $\mathrm{CaCO}_{3}$ crystals precipitated in the presence of $1 \mathrm{gL}^{1}$ poly(ethylene oxide) block poly (methacrylic acid) at $\mathrm{pH} 10 .^{[56]}$ 
in the central region manifests itself in an increasing misalign ment of the domains towards the outer edges of the aggregate where the energy can be more readily dissipated. This situation could lead to complex morphologies if the crystals continue to grow by solution processes because secondary nucleation would occur specifically at the misaligned surface sites to produce an angular spread of crystal outgrowths. The switching between aggregation and solution mechanisms could, for example, explain the time dependent "rod to dumbbell to notched sphere" evolution of forms that has been often observed when fluoroapatite, ${ }^{[57,58]}$ calcium car bonate, ${ }^{[59,60]}$ and barium sulfate ${ }^{[49,55]}$ crystals grown in the presence of macromolecules, such as specially designed block copolymer additives. ${ }^{[61]}$ The transformation between rod, dumbbell, and spheroidal morphologies can be controlled to some extent by changes in the concentration ratio of polymer to mineral, ${ }^{[56]}$ variations in the solvent composition in alcohol/ water mixtures. ${ }^{[62]}$ or by changing the strength of interaction between the polymer and crystal by variations in $\mathrm{pH}$ value. ${ }^{[55]}$

\section{Mesoscale Self-Assembly of Nanoparticle Arrays}

Implicit in the previous discussion is the assumption that occluded macromolecules do not completely prevent restruc turing of the nanocrystal containing aggregates. That is, crystallographically continuous junctions are formed between the nanocrystal building blocks even when significant num bers of defects are introduced. An interesting situation arises when the binding affinity of the organic molecules is sufficiently high that the nanocrystals are so highly stabilized that no further crystal growth can take place within the aggregates. In such cases, the nanoparticles can become ordered by organic interactions at the interfaces between the hybrid building blocks. If the nanocrystals have high shape anisotropy, then highly organized nanoparticle arrays and higher order superstructures can spontaneously assemble (Figure 5).

The construction of organized nanoparticle based struc tures by self assembly or templating is a key goal of nano tectonics, as reviewed in detail elsewhere. ${ }^{[63,64]}$ Herein we

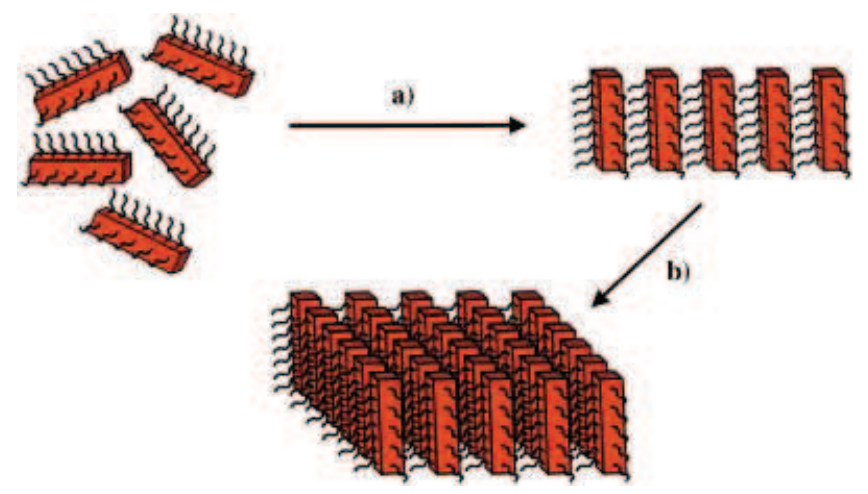

Figure 5. a) Mesoscale assembly of crystalline hybrid nanoparticles through face specific surface conjugation or mesophase ordering between adsorbed organic molecules, b) higher order assembly associ ated with 2D superstructure formation. focus specifically on the mesoscale self assembly of organic coated crystalline nanoparticles. This process occurs readily, for example, in the presence of surface anchored surfactant molecules. ${ }^{[4,65]}$ In most cases, the nanoparticles (such as, Au $\mathrm{Ag}, \mathrm{CdSe}(\mathrm{S})$ ) are spherical so the corresponding super structures have close packed lattices in two or three dimen sions. Hydrophobic interactions between surfactant mole cules on adjacent nanoparticles drive the assembly, which is usually reversible unless interparticle cross linkers are intro duced to stabilize the superstructure. For example, organic dithiols have been used as bridging molecules in superlattices of hydrophobic Au nanoparticles. ${ }^{[6]}$ Recent studies have focused on the mesoscale assembly of non close packed superstructures by using surfactant coated nanoparticles with high shape anisotropy, such as nanorods of $\mathrm{BaCrO}_{4},{ }^{[67]}$ $\mathrm{Au},{ }^{[68]}$ and cobalt. ${ }^{[69]}$ These nanocrystals have surfaces that are flat or exhibit low curvature, so the hydrophobic forces can be strengthened by collective intermolecular interactions, which, for example, result in stable surfactant bilayers between the inorganic particles. In such cases, disorder to order meso phase transitions associated with the pendent surfactant molecules are responsible for the strong interparticle driving force that can operate over long length scales to produce liquid crystalline inorganic assemblies. ${ }^{[70]}$

The sensitivity of these ordering transitions to changes in the interaction potential between the crystal surface and associated surfactant molecules has been highlighted by using the interfacial activity of microemulsion based reaction fields to interactively couple the synthesis of $\mathrm{BaCrO}_{4}$ or $\mathrm{BaSO}_{4}$ nanocrystals with their self assembly into higher order struc tures. ${ }^{[67]}$ The reaction occurs at room temperature in unstirred isooctane that contains a mixture of $\mathrm{Ba}(\mathrm{AOT})_{2}(\mathrm{AOT}=\mathrm{bis}(2$ ethylhexyl)sulfosuccinate) reverse micelles and water in oil microemulsion droplets prepared from NaAOT and aqueous chromate or sulfate anions. When mixed together at a $\mathrm{Ba}^{2+}: \mathrm{CrO}_{4}{ }^{2-}\left(\mathrm{SO}_{4}{ }^{2-}\right)$ molar ratio of $1: 1$, slow exchange between the droplets gives rise to the spontaneous assembly in solution of linear chains of crystallographically aligned prismatic nanoparticles spaced at a distance of $2 \mathrm{~nm}$ from each other (Figure 6). Formation of the linear array depends

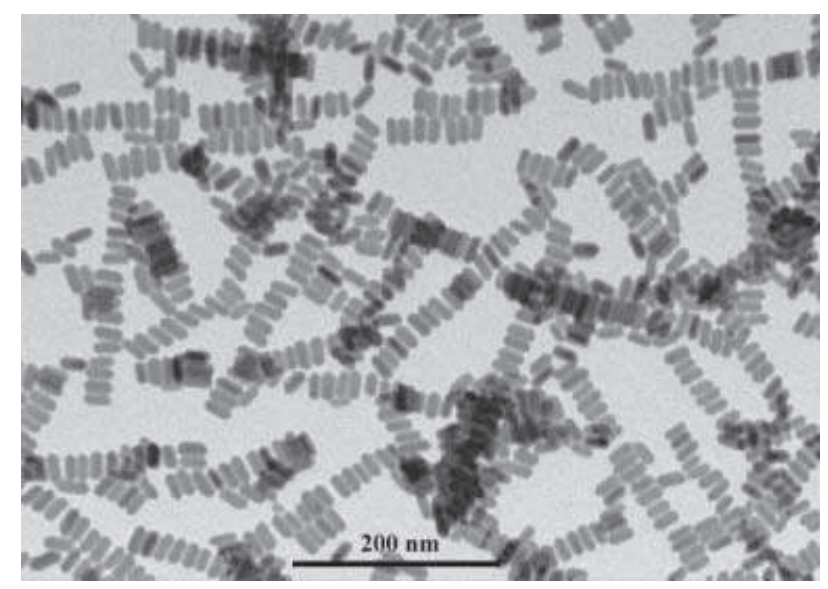

Figure 6. TEM image showing ordered chains of prismatic $\mathrm{BaCrO}_{4}$ nanoparticles prepared in AOT microemulsions at $\left[\mathrm{Ba}^{2+}\right]:\left[\mathrm{SO}_{4}{ }^{2}\right] \approx 1$ and $w \quad 10$. 
on the uniformity in nanoparticle size and shape anisotropy, which facilitate crystal face specific interactions between the hydrophobic tails of surface adsorbed surfactant molecules. The driving force for assembly appears to involve a meso phase transition in which the unordered pendent AOT molecules are organized into an interdigitated bilayer between adjacent nanoparticles. This process is sensitive to changes in the molar ratio of reactants, which can strengthen or weaken the binding of anionic AOT molecules to the surface of the growing nanoparticles. For example, no assembled chain structures are found if the anion concen tration is two to five times less or greater than that of the $\mathrm{Ba}^{2+}$ ions. In the latter case, discrete crystalline nanoparticles are observed presumably because attractive interactions between the anionic headgroups of AOT and the crystal surface are significantly reduced by the negative surface charge associ ated with excess chromate or sulfate anions in the boundary layers. Thus, the surfactant molecules remain in a fluid state at the water oil interface of the microemulsion droplets rather than being expelled from the interface and immobilized by surface anchoring, with the consequence that there is no significant driving force for interparticle bilayer formation. On the other hand, an excess of $\mathrm{Ba}^{2+}$ ions significantly increases the surfactant inorganic component interactions such that the assembly process becomes dependent on coupled mesoscale transformations, as described in detail in Section 5.

Mesoscale self assembly of nanoparticle based structures is also expected to occur in the presence of surface adsorbed macromolecules such as polymers and biomolecules. Signifi cantly, anchoring of biological macromolecules, such as DNA, antibodies, and biotinylated proteins, can significantly increase the informational content of the building blocks because the nondirectional electrostatic forces of the inor ganic surface are replaced with organic sites for molecular recognition. For example, complementary single stranded oligonucleotides can be attached to different populations of $\mathrm{Au}$ nanocrystals, and when mixed together give rise to spontaneous assembly because of base pairing and duplex formation between the particles. ${ }^{[71,72]}$ Changing the number of bases in the synthetic oligonucleotides influences the inter particle separations, whereas variations in nanoparticle mor phology can be used to produce anisotropic superstructures. ${ }^{[9]}$

It is well known that amphiphilic block copolymers exhibit mesophase transitions analogous to those observed for surfactant molecules, so the formation of assembled nano crystal based arrays should also be possible using surface adsorbed synthetic macromolecules. To date, however, most examples of polymer induced nanoparticle assembly involve phase separation of hydrophilic and hydrophobic segments, along with preferential demixing of the nanocrystals into one of these blocks. ${ }^{[7376]}$ On the other hand, polymer induced nanoparticle assembly in aqueous solution has been generally concerned with amorphous building blocks. These include metastable phases, such as amorphous calcium carbonate and barium sulfate (see Section 6), as well as amorphous silica, which is stable at room temperature and pressure. In particular, poly(ethylene oxide) di and triblock copolymers have been extensively used for the template directed syn thesis of ordered mesoporous silicas, ${ }^{[77}$ 79] in which the aggregation of silica oligomers and primary particles is patterned by phase transitions that organize the macromole cules into hexagonal, lamellar, or cubic liquid crystalline structures. Similar mechanisms involving the mesophase separation of cationic biomolecules, such as long chain poly amines and proteins (silaffins), have been proposed to explain the nanoscale patterning of diatom biosilica. ${ }^{[80,81]}$ These models propose that biosilica patterning occurs on various length scales because of consecutive phase separation of polyamine containing droplets ${ }^{[80]}$ or aggregates ${ }^{[81]}$ associated with incipient polymerization and aggregate densification, respectively.

It is important to emphasize that in these polymer based mechanisms the organization of the silica particles arises by exclusion of the building blocks from certain regions of space through phase separation (droplet/aggregate formation) or liquid crystalline transitions. This situation is fundamentally different from the concerted assembly of hybrid building blocks, described in the first part of this section, in which nanocrystals are intimately interconnected with organic molecules. Moreover, unlike the nanocrystal systems descri bed, the silica based processes are transformable in the sense that the primary particles continue to grow to some extent during polymer induced organization. This occurrence leads us to the interesting and important situation in which the assembly process proceeds by aggregation of hybrid building blocks consisting of amorphous interiors that are intrinsically unstable with respect to crystallization. In the next section, we discuss the influence of these transformations on the meso scale assembly of hybrid nanomaterials.

\section{Mesoscale Transformations and Emergent Nanostructures}

Under certain circumstances, strong binding interactions between organic molecules and inorganic nuclei severely inhibit lattice construction such that colloidal aggregates containing hybrid primary particles with metastable amor phous cores are deposited. With time, however, the amor phous nanoparticles slowly crystallize within the aggregates, and this process can be strongly coupled with mesophase transitions involving surface adsorbed polymers or surfac tants (Figure 7). For example, growth of rod and platelike nanocrystals would reduce the curvature imposed on the surface anchored molecules, such that favorable changes in the inorganic lattice and organic bending energies can occur by cooperative mesoscale transformations. As these processes occur slowly within the confined field of the aggregates, nanocrystals with high shape anisotropy can be produced. Moreover, because the resulting nanocrystals are "coded" by the surface organization of the attached organic molecules, interparticle interactions involving, for example, hydrophobic interactions and bilayer interdigitation can lead to the in situ mesoscale assembly of interconnected hybrid nanostructures (Figure 7). The interactive nature of these processes deter mines the time dependent coupling between crystallization and associated adaptations in the organization of the surface 


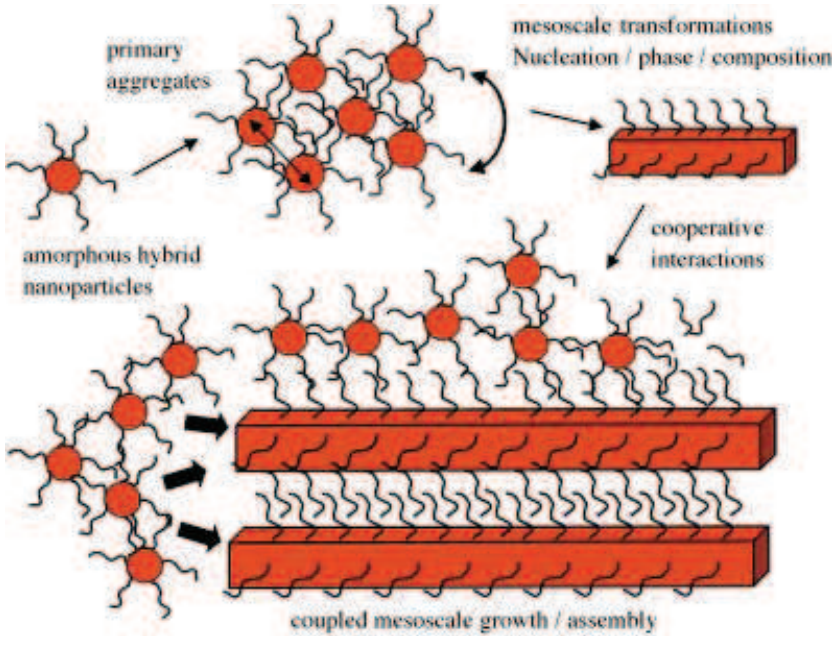

Figure 7. Proposed mechanism of coupled mesoscale transformations and emergent hybrid nanostructures. Transformation of the primary hybrid aggregates occurs by cooperative reorganization of the inor ganic lattice energy (double headed straight arrow) and mesostructure of the surface adsorbed organic molecules (double headed curved arrow). Higher order cooperative interactions give rise to emergent behavior and the embedding of structures on different length scales.

attached molecules. As a consequence, a series of cooperative feedback loops can be established and the systems are then notable for their emergent properties that are expressed across a range of length scales.

The above concepts are based on several recent studies on the morphosynthesis of macroscopic structures consisting of higher order assemblies of surfactant inorganic crystalline nanofilaments of $\mathrm{BaSO}_{4}, \mathrm{BaCrO}_{4}$, and $\mathrm{Ba}$ phosphotung state $,{ }^{[82]} \mathrm{BaCO}_{3},{ }^{[83]} \mathrm{CaSO}_{4},{ }^{[84]}$ or $\mathrm{CaCO}_{3} \cdot{ }^{[85]}$ These structures were synthesized in water in oil microemulsions, but signifi cantly, similar complex architectures can be prepared in aqueous supersaturation solutions. For example, barium sulfate and chromate nanofilament bundles and cones were obtained in aqueous solutions of anionic polyelectrolytes ${ }^{[86,87]}$ or hydrophilic block copolymers with a polyanionic domain. ${ }^{[86,88]}$ Nested neuronlike tangles of calcium phosphate nanofilaments have been prepared within aggregates of a partially alkylated poly(methacrylic acid) block poly(ethy lene oxide) copolymer ${ }^{[89]}$ or polyaspartate solutions, ${ }^{[90]}$ in addition $\mathrm{Ag}$ nanowires ${ }^{[91]}$ or calcite dumbbells ${ }^{[56]}$ were pro duced from amorphous precursor particles in the presence of poly(ethylene oxide) block poly(methacrylic acid) copoly mers.

The requirement for strong binding interactions between the adsorbed organic molecules and the inorganic surface during the nucleation and initial growth stages has been clearly demonstrated by changing the cation:anion molar ratio of reactions in microemulsions. ${ }^{[67,82]}$ As discussed in Section $4, \mathrm{Ba}^{2+}: \mathrm{CrO}_{4}{ }^{2-}\left(\mathrm{SO}_{4}{ }^{2-}\right)$ molar ratios of $1: 1$ or $1: 5$ give rise to surfactant linked chains or discrete surfactant coated nanoparticles as a result of intermediate and low levels of surfactant binding, respectively. In contrast, at molar ratios of $5: 1$, there is a large excess of $\mathrm{Ba}^{2+}$ ions such that the initially formed nanoparticles are positively charged and the anionic surfactant molecules are strongly adsorbed onto the inorganic surfaces. This produces amorphous rather than crystalline nanoparticles of $\mathrm{BaCrO}_{4}$ and $\mathrm{BaSO}_{4}$ that are constrained to $5 \mathrm{~nm}$ in size and which slowly aggregate because of hydro phobic interactions between the surface anchored surfactant chains (Figure 8a). Amazingly, groups of nanoparticles line up in linear arrays that fuse together and crystallize into $5 \mathrm{~nm}$ wide single filaments coated with AOT surfactant molecules (Figure $8 \mathrm{~b}$ ). ${ }^{\left[{ }^{[2]}\right]}$ With time, other crystalline filaments are formed parallel to the original thread to produce a small bundle held together by surfactant bilayers (Figure $8 \mathrm{c}$ ). The locking in of new filaments by surfactant interdigitation generates a bending force in the bundle to give a coiled spiral at one end, which can perpetuate throughout the whole length of the bundle to produce structures with helical and conelike forms.

The binding strength and corresponding degree of coop erativity associated with mesoscale disorder order transfor mations and surfactant reorganization is not only influenced by the surface charge (molar ratio) but also the degree of hydration of the inorganic surface and surfactant headgroups. The amount of water in the above experiments is extremely small ([water]/[surfactant], molar ratio $w=10)$ but turns out to be optimal as lower water contents are not sufficient to drive the amorphous $\rightarrow$ crystal transformation, whereas higher levels increase the size of the droplets such that the crystallization process is no longer influenced by the surfac tant membrane. Similar observations have been reported when different amounts of water in isooctane NaAOT micro emulsions of constant droplet size $(w=10)$ are added to isooctane dispersions of alkylbenzenesulfonate coated amor phous calcium carbonate (ACC) nanoparticles. ${ }^{\left[{ }^{[5]}\right.}$ Hydration of the ACC nanoparticles results in aggregation followed by
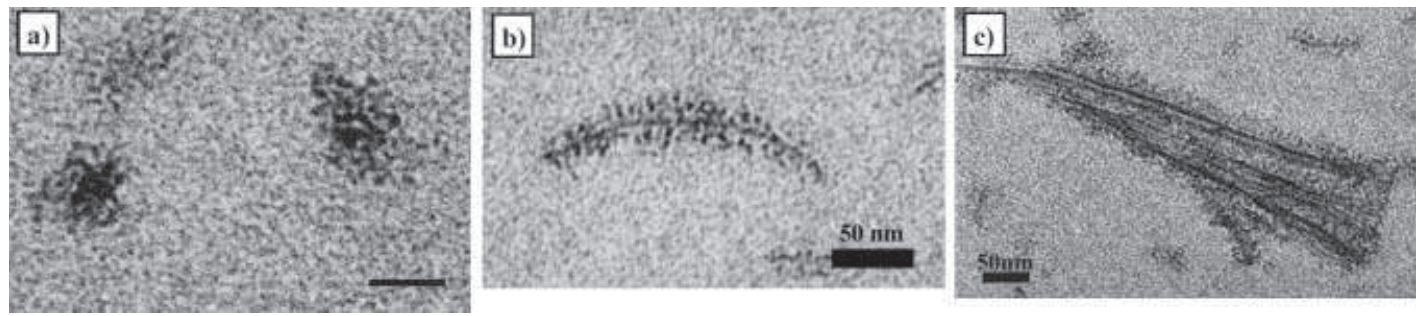

Figure 8. Early stages of $\mathrm{BaSO}_{4}$ nanofilament formation in water in oil microemulsions: ${ }^{[82]}$ a) aggregates of electron dense $5 \mathrm{~nm}$ sized surfactant coated amorphous particles ( $1 \mathrm{~h}), \mathrm{b})$ nucleation and growth of crystalline nanofilament within a matrix of electron dense nanoparticles (2 $3 \mathrm{~h})$, c) nucleation and growth of secondary filaments alongside the primary thread to produce aligned bundles ( $5 \mathrm{~h})$. Scale bars $50 \mathrm{~nm}$. 


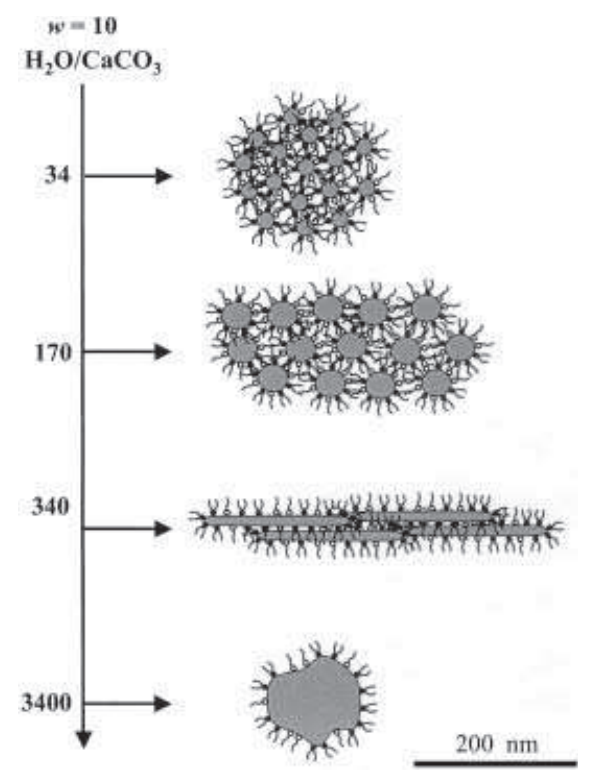

Figure 9. General scheme showing effect of [water droplet]/[amor phous $\mathrm{CaCO}_{3}$ nanoparticle] ratio $(n)$ at a constant [water]/[surfactant] molar ratio $(w)$ of 10 on the types of hybrid surfactant vaterite nano structures synthesized by microemulsion mediated phase transforma tion of surfactant stabilized ACC nanoparticles. ${ }^{[85]}$ The aggregated structures are drawn approximately to scale.

water induced crystallization and the formation of organized hybrid nanostructures by mesoscale transformations that are mediated by the extent of coupling at the surfactant inor ganic interface (Figure 9). Strong coupling in the presence of low amounts of water $\left(\left[\mathrm{H}_{2} \mathrm{O}\right] /\right.$ $\left.\left[\mathrm{CaCO}_{3}\right], n=34\right)$ gives monodisperse spheroi dal aggregates of densely packed $5 \mathrm{~nm}$ diame ter surfactant coated vaterite nanoparticles, whereas weak interactions at $n=3400$ produce discrete vaterite nanoparticles, $130 \mathrm{~nm}$ in size. Significantly, intermediate levels of coupling produce anisotropic nanostructures, such as spindle shaped aggregates of $18 \mathrm{~nm}$ sized vater ite nanoparticles $(n=170)$ and high aspect ratio bundles of aligned $10 \mathrm{~nm}$ wide twisted vaterite nanofilaments $(n=340)$, both of which are assembled by surfactant interdigitation between adjacent particles.

The above results indicate that the trans formation pathways of amorphous barium sul fate or calcium carbonate are determined by the extent of water penetration into the primary cores and the effect of this on electrostatic interactions at the mineral surfactant interface. The process can be coupled synergistically because the transformations take place in a hydrophobic solvent; thus it is very surprising that analogous nanostructures can be prepared in aqueous media containing certain water soluble polymers. For example, the crystalliza tion of $\mathrm{BaSO}_{4}$ in the presence of a partially phosphonated poly(ethylene oxide) block poly (methacrylic acid) copolymer (PEO $b$ PMAA $\mathrm{PO}_{3} \mathrm{H}_{2}$ ) under quiescent conditions yields bundles of coiled single crystalline nanofilaments ${ }^{[86]}$ similar to those observed in the micro emulsion based system discussed above. Secondary nuclea tion of filaments preferentially along the length of the bundles gives rise to cone shaped structures that splay outwards towards their growth edges (Figure 10a), possibly because of packing pressures associated with the increased thickness. The fiber bundles often show flat growth edges as a result of a self healing mechanism in which surface defects are filled with nanoparticle building units under energy gain. Related studies on $\mathrm{BaCrO}_{4}$ crystallization also in the presence of PEO $b$ PMAA $\mathrm{PO}_{3} \mathrm{H}_{2}$ showed that sheets of organized nano filaments could be produced along with the cone shaped bundles. ${ }^{[88]}$

Significantly, in common with the microemulsion systems, these polymer mediated crystallization processes involve the presence of nanometer sized amorphous precursor particles prior to the nucleation of crystalline nanofilaments. Whereas the water content was crucial for the surfactant mediated stabilization of the amorphous precursor in the microemul sions, interactions between the amorphous phase and phos phonated block copolymer appear to be sufficiently strong that crystallization is inhibited even in the presence of a vast excess of water. The polymer coated amorphous precursor particles slowly coalesce into colloidal aggregates (Fig ure $10 \mathrm{~b}$ ), followed by heterogeneous nucleation of the crystalline phase and anisometric growth (Figure 10c) in accordance with the model of coupled mesoscale trans formation (see Figure 7).
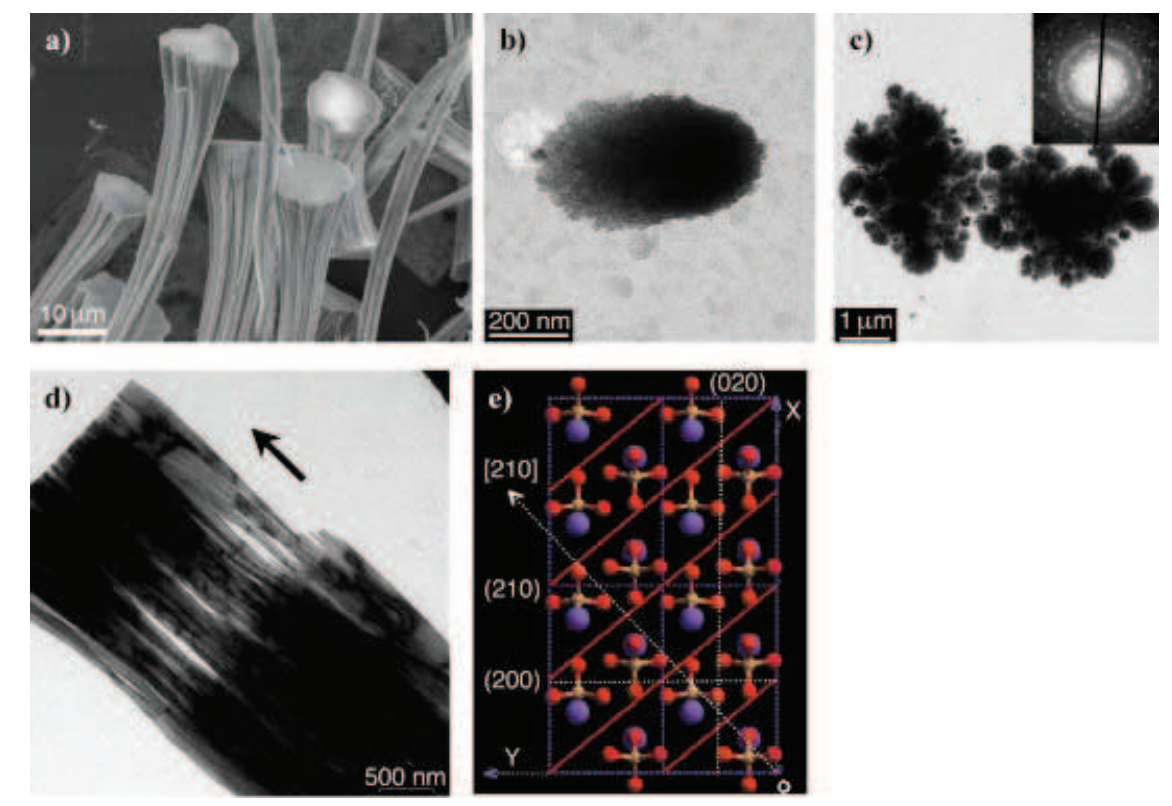

Figure 10. Crystallization of $\mathrm{BaSO}_{4}$ in presence of $1 \mathrm{gL}{ }^{1} \mathrm{PEO} b$ PMAA PO${ }_{3} \mathrm{H}_{2}(21 \%$ phosphona tion) at $\mathrm{pH} 5::^{[86]}$ a) SEM image of mature $\mathrm{BaSO}_{4}$ fiber bundles, b) TEM image showing aggregate of amorphous particles after $1 \mathrm{~h}, \mathrm{c}$ ) TEM image showing development of crystalline nanofilament bundles within cone shaped aggregate of amorphous nanoparticles after $3 \mathrm{~h}$. The cones nucleate on the TEM substrate and are viewed preferentially along their long axis, d) high magnification TEM image showing growth edge and individual nanofilaments; arrow indicates the direction of the [210] axis, e) plot of barite crystal structure viewed perpendicular to the [210] axis (shown by arrow). The (210) face is identified by the red lines and contains coplanar $\mathrm{Ba}^{2+}$ and $\mathrm{SO}_{4}{ }^{2}$ ions. 
As for the surfactant mediated microemulsion system, the high shape anisotropy indicates preferential adsorption and redistribution of polymer molecules onto certain crystal faces during growth. In the case of the phosphonated block copolymer, this leads to preferred growth along the [210] crys tallographic axis, that is, perpendicular to the negatively charged (210) face (Figure $10 \mathrm{~d}, \mathrm{e}$ ), which presumably does not interact as strongly with the anionic polymer as the faces parallel to the [210] axis. One possibility is that the vectorial growth is also facilitated by electric fields around the crystal nuclei that direct the attachment of amorphous primary particles present in the aggregate specifically to the tips of the nascent nanofilaments. ${ }^{[86]}$ The high level of crystallographic coherence could also originate from the elimination of high energy surfaces by oriented particle attachment at the ends of the growing nanofilaments, as observed in other systems (see Section 3) $\cdot{ }^{[34]}$ It is remarkable that such vectorially controlled nanoparticle fusion leads to defect free filaments that have a diameter of a few tens of nanometers but can grow as long as a hundred microns.

A remarkable feature of these systems is their emergent behavior in which self similar structures become embedded in higher order architectures as the length scale is extended from the meso to macro level. The cone structures appear to originate from single sheets of nanofilaments during the very early development stage by edge to edge attraction and fusion, followed by splaying as a result of lateral packing forces. The process is strongly temperature dependent as shown for $\mathrm{BaCrO}_{4}$ where the self similar structures develop by slow transformation over days at low temperature, whereas nanofilament sheets and spherical aggregates are produced at room temperature and $100^{\circ} \mathrm{C}$, respectively. ${ }^{[88]}$ Amazingly, the cones are assembled within hierarchical architectures (Figure 11), particularly if the degree of phosphonation of the block copolymer is reduced such that the crystallization inhibition capacity is lowered to a level where higher order interactions can take place. Multilevel architectures consist ing of several generations of cones (Figure 11a) originate from the secondary nucleation of new cones on the rim of existing ones. Surprisingly, this stops the growth of the parent cone even though much of the original rim remains exposed, such that the growth edge becomes smooth and inert. A self
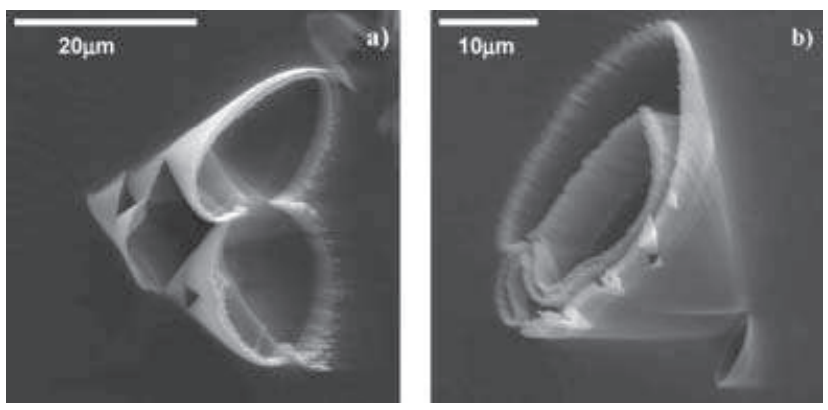

Figure 11. SEM images of higher order $\mathrm{BaCrO}_{4}$ nanofilament based structures produced in the presence of $1 \mathrm{gL}{ }^{1} \mathrm{PEO} b$ PMAA $\mathrm{PO}_{3} \mathrm{H}_{2}$ (1\% phosphonation) at $\left.\mathrm{pH} 5:{ }^{[88]} \mathrm{a}\right)$ cone on cone and b) cone in core hierarchical forms. limiting growth mechanism has been proposed based on a critical length associated with the progressive increase in dipole moment along the nanofilaments as they extend in size. ${ }^{[88]}$ Beyond this length, heterogeneous nucleation of a new generation of cones on the rim of the existing structures becomes energetically more favorable than further extension of the rim.

It is noteworthy that similar hierarchical nanofilament based cone structures have also been reported for the crystallization of $\mathrm{BaSO}_{4} / \mathrm{BaCrO}_{4}$ in the presence of low molar mass polyacrylate. ${ }^{[86,87]}$ Although the hierarchical cone structures were only obtained within a limited window of experimental conditions, the much simpler molecular archi tecture of the polymer additive implies that at least three general requirements have to be fulfilled by the polymer. 1) the molecular length and/or structure must prevent bridg ing flocculation otherwise the transformation dynamics are severely curtailed. 2) rapid crystallization must be inhibited so that partially stabilized amorphous nanoparticles are produced. 3) the polymer must selectively adsorb on specific crystal faces once the nanocrystal is formed to induce vectorial growth and assembly. Although many polymers might meet these criteria, only a limited number have been identified to date.

The above examples indicate that the formation of macroscopic architectures with embedded structures involves a continuous supply of hybrid nanoparticle precursors to the growth sites of crystals formed initially in association with mesoscopic aggregates. This process can occur over relative long periods of time (days and weeks) as a result of the prolonged nucleation of the amorphous phase by slow release of sequestrated cations from soluble macromolecules, or by delayed aggregation associated with the solvation of surfac tant molecules in hydrophobic solvents. In such cases, emergence of the multiscale structures from mesoscopic processes is also dependent on solution based properties, so that changes in temperature and additive concentration can significantly influence the nature of the final prod ucts. ${ }^{[56,82,86,88]}$ In contrast, other studies have highlighted alternative scenarios of morphosynthesis in which macro scopic deposits of the amorphous hybrid precursors are produced by phase separation from the reaction solution. The precursor can take the form of liquid droplets that are enriched in polymers, inorganic ions, and clusters referred to as a polymer induced liquid precursor (PILP) process ${ }^{[92]}$ which together act as a "solute melt" for catastrophic crystal nucleation. For example, liquid liquid phase separation of $\mathrm{CaCO}_{3} /$ polyaspartate droplets gives rise to amorphous hybrid films by coalescence and sedimentation, followed by solid ification into crystalline sectors often with nonequilibrium morphologies. ${ }^{[3]}$ Similarly, catastrophic crystallization of calcium phosphate within phase separated liquid droplets of polyaspartate or polyacrylate prior to sedimentation results in $300 \mu \mathrm{m}$ diameter spheres with complex radially banded growth textures (Figure 12). ${ }^{[94]}$ The large internal strain associated with rapid crystallization of the multilayered hybrid interior is sufficient to cause fragmentation into cone shaped domains if the spheres are subjected to small mechanical forces. 


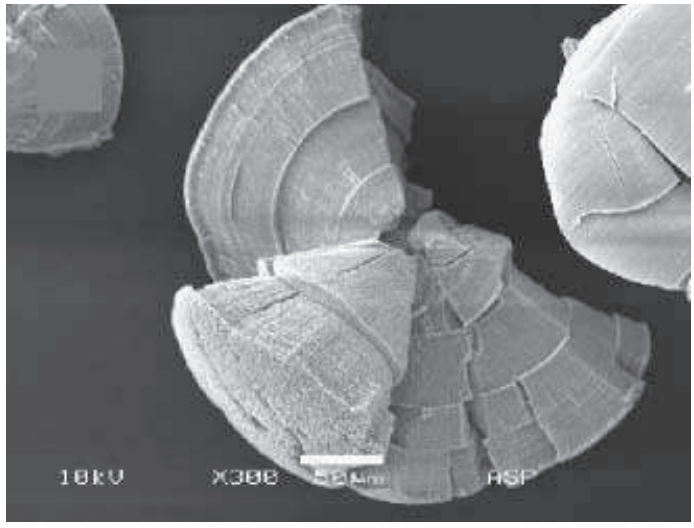

Figure 12. SEM micrograph of a fractured octacalcium phosphate poly aspartate spheroid showing complex banded texture. ${ }^{94]}$ The sample was isolated after $45 \mathrm{~min}$; scale bar, $50 \mu \mathrm{m}$.

Introduction of solid substrates into the above processes of inorganic organic coupled mesoscale transformations can result in physical or chemical alignment of the nanostructures with an external surface. Indeed, in the case of the polymer mediated $\mathrm{BaSO}_{4} / \mathrm{BaCrO}_{4}$ nanofilament superstructures het erogeneous nucleation on the glass walls or TEM grids (see Figure $10 \mathrm{c}$ ) is fundamental to their formation; crystallization experiments in plastic bottles failed to reproduce the fibers. Thus, it should be possible in general to synthesize oriented assemblies of emergent nanostructures by interfacial control of hybrid mesoscale transformations using template surfaces with appropriate structure and chemistry. Moreover, similar strategies may be of direct relevance in organic matrix mediated processes of oriented nucleation in biomineraliza tion, which we now discuss in detail.

\section{Mesoscale Transformations and Matrix-Mediated Nucleation in Biomineralization}

Although the study of biomineralization ${ }^{[95]}$ has a long and venerable history, it is only during the last two decades that the field has become notable as a rich source of ideas and concepts in modern materials chemistry. ${ }^{[96,97]}$ For centuries, knowledge of biomineralized systems has provided detailed and reliable descriptions of biologically produced inorganic deposits relevant to fields such as medicine, taxonomy, and paleontology. However, only with the input of physical chemical principles during the 1960 s and 70 s did these diverse areas of biomineralization become integrated within a gen eral conceptual framework. Above all, the introduction of key ideas borrowed from crystallization theory such as super saturation, nucleation and growth mechanisms, substrate induced oriented nucleation (epitaxy), and habit modifica tion along with concurrent advances in instrumentation (notably, electron microscopy), played a central role in transforming the field. The coupling of these classical models with an increased knowledge of biological systems gave rise in particular to the notion of organic matrix mediated biomineralization, as elaborated in a seminal paper by Lowenstam in 1981. ${ }^{[98]}$
A key aspect of this theory concerns the role of molecular interactions in controlling oriented nucleation at the matrix mineral interface. ${ }^{[99}{ }^{101]}$ The model proposes that a structural and geometric match exists between lattice spacings in certain crystal faces and distances that separate functional groups periodically arranged across an organic surface associated with a macromolecular matrix or lipid vesicle bilayer. The conventional view is that aqueous cations bind at these sites to form a $2 \mathrm{D}$ array, followed by binding of counteranions and cluster formation, which results in oriented nucleation as a result of the lowering of the activation energy for a specific crystallographic face (Figure 13, pathway A). A similar out come can arise from the matrix binding of crystalline nuclei formed either directly from solution or by phase transforma tion of amorphous clusters in solution (Figure 13 pathway B). In this case, collective interactions involving crystal surfaces on the preformed nuclei and charged/polar groups on the organic matrix are responsible for the preferred crystallo graphic orientation.

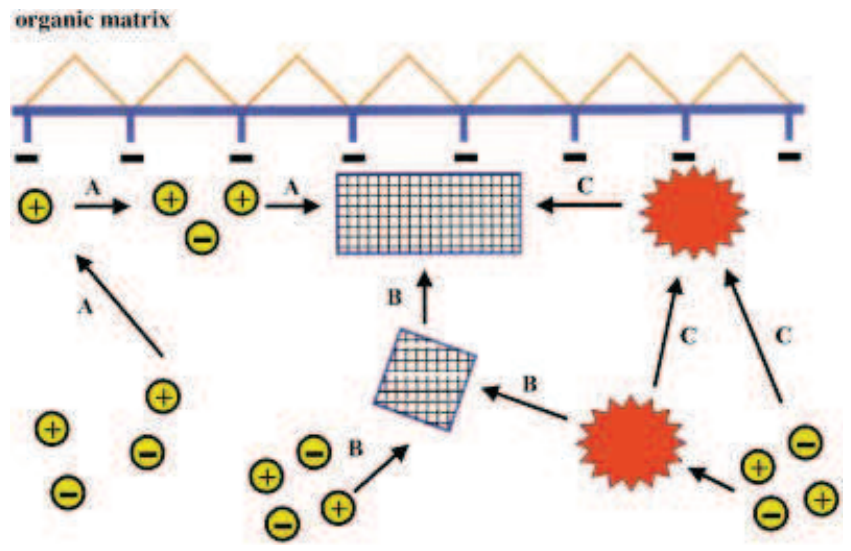

Figure 13. Classical and extended models of organic matrix mediated oriented nucleation in biomineralization. See text for details.

In light of the discussions in Section 5, we propose an alternative mechanism in which amorphous primary particles formed by ion or cluster binding at the organic surface undergo coupled matrix mediated mesophase transforma tions that result in oriented crystallization (Figure 13, path way C). As discussed above, depending on the nature and strength of interactions at the inorganic organic interface, transformations of amorphous nanoparticles can become vectorially regulated within aggregates to produce crystallo graphically oriented hybrid nanostructures. Thus, it seems possible that the oriented nucleation and initial growth of biominerals could be determined by cooperative processes involving phase transformations at the mesoscopic level, as well as by molecular based mechanisms such as described in classical theories of organic matrix mediated epitaxy.

Our extended model postulates that crystal nucleation and the initial stages of growth occur within an interfacial layer, such as a thin gel like film of transformable macro molecules, some of which are anchored by connectors to the structural component of the organic matrix or vesicle bilayer 


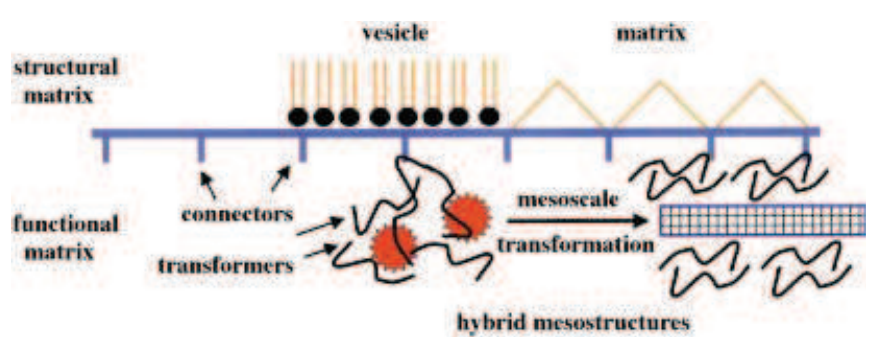

Figure 14. Matrix mediated interfacial control of coupled mesoscale transformations in oriented nucleation and growth of biominerals.

(Figure 14). Possible candidate biomolecules include: sulfated polysaccharide PS2 in coccoliths, ${ }^{[102]}$ multifunctional shell matrix proteins, MSI60 and N16, ${ }^{[103]}$ and lustrin A, ${ }^{[104]}$ and collagen binding proteins, such as osteonectin. ${ }^{[105]}$ We propose that crystallization proceeds within this interfacial layer by mesoscale transformation of hybrid aggregates consisting of intimately associated amorphous inorganic nanoparticles and adsorbed macromolecules. In support of this mechanism, there are several examples of hybrid nanoparticles produced during the early stages of biomineralization, for example, in sea urchin embryo spiculogenic cells, ${ }^{[27]}$ in association with coccolith polysaccharides, ${ }^{[106]}$ rat dentin phosphoproteins, ${ }^{[107]}$ phosphoproteins from several species of bivalve molluscs, ${ }^{[108]}$ and as coatings on oyster shells. ${ }^{[109]}$ The model considers crystallization to occur within these hybrid aggregates by coupled inorganic organic interactions, as discussed in Sec tion 5. The matrix is therefore no longer viewed as a static structural/functional template with binding potential for directed nucleation, but as comprising a dynamic interface that is inherently reactive and subject to mesoscale trans formation. In addition, molecular recognition is not consid ered to be the principal driving force but is replaced by multilevel interactions that induce preferential orientation with respect to the structural matrix as an emergent property of the system.

It is important to note that similar processes could give rise to oriented crystallization even in the absence of a physical surface for instance when the matrix is "internal ized" within an isotropic gel monolith provided that some stress field is imposed on the system. For example, the initial stages of enamel formation occur in a gel of amelogenin

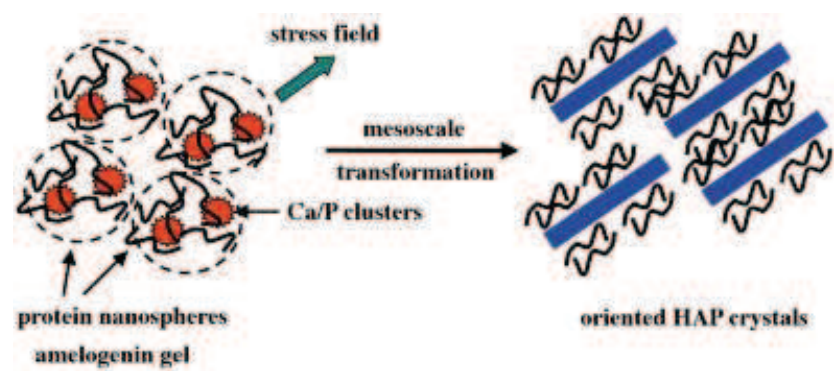

Figure 15. Stress induced alignment of mesoscale transformations within gel like organic matrices involved in biomineralization. The scheme shows a mechanism for oriented crystallization of hydroxyapa tite (HAP) nanofilaments in dental enamel. protein nanospheres, ${ }^{[110]}$ and we propose that loading the organic aggregates with calcium phosphate clusters results in a coupled mesoscale transformation, which in the presence of an applied stress field produces an oriented array of ribbon like carbonated hydroxyapatite nanocrystallites and associ ated macromolecules (Figure 15). The stress field could originate internally through progressive changes in densifica tion, or externally through the action of adjacent cells. Similar mechanisms might apply to proteoglycans in cartilage, ${ }^{[111]}$ and polysaccharides, such as chitin in mineralized molluscan teeth. ${ }^{[112]}$

\section{Summary and Outlook}

In this review we have attempted to establish some principles and concepts that elucidate the potential of syn thesis construction pathways involving mesoscale self assem bly and transformation processes. We have focused in particular on the interplay of aggregation and crystallization, and their influence on the cooperative reorganization of inorganic and organic building blocks and emergence of higher order architectures with embedded structures. The following conclusions have been highlighted:

- Kinetic pathways of crystallization involve multistep pathways that if regulated, for example, by macromole cules and surfactants, could significantly increase the scope for controlled materials synthesis.

- Amorphous phases are prominent in kinetic pathways of crystallization and can be stabilized by organic macro molecules or transformed into crystalline phases, some of which (Mg calcite, for example) may have high isomor phic substitutions.

- Crystal growth by the ordered aggregation of preformed crystalline building blocks is a mesoscale assembly process that results in single crystals with iso oriented mosaic textures. The size and shape of the nanosized building blocks influence crystal morphology, and restructuring and/or oriented attachment at the particle particle inter faces is required for long range crystallographic continu ity.

- Macromolecules and surfactants can bind to nanocrystal surfaces to produce inorganic organic particles with shape and size specificity that can act as hybrid building blocks in aggregation based pathways of crystal growth. Occlusion of surface bound organic molecules influences the crystal texture and at high concentrations results in crystallographic discontinuities and the evolution of complex morphologies.

- Stabilized hybrid building blocks with shape anisotropy undergo mesoscale self assembly to produce organized nanoparticle based superstructures linked by organic connectors. The driving force for assembly can originate from disorder order mesophase transitions, such as the formation of interparticle surfactant bilayers, or molec ular recognition between biomolecules, such as single stranded oligonucleotides. Another possibility not dis cussed in this review is the formation of hybrid nano composites through synthesis and self assembly. ${ }^{[113,114]}$ 
- Amphiphilic polymers can influence the assembly of amorphous silica nanoparticles by phase separation and liquid crystalline phase transitions. These processes are influenced by incipient changes in aggregation and densification to produce patterned materials.

- Emergent processes involving coupled mesoscale trans formations within aggregates of hybrid building blocks with metastable amorphous interiors can give rise to the spontaneous assembly of crystalline nanostructures with complex form and higher order organization. Such struc tures are mediated by surface adsorbed surfactants or polymers, and are propagated across a range of length scales to produce hierarchical self similar architectures.

- Coupling of amorphous to crystal transformations with surfactant or macromolecular reorganization is strongly influenced by electrostatic interactions and the degree of hydration at the inorganic organic interface, as well as the hydrophobic and van der Waals attractive forces between the surface adsorbed organic molecules.

Finally, we used the above concepts to suggest some new ideas about oriented nucleation in biomineralization. The conven tional model of molecular recognition at the organic inor ganic interface was extended to consider the role of matrix mediated mesophase transformations involving aggregates of macromolecules and amorphous primary particles located at the organic surface or in the form of structured gels. In the past, biomineralization studies have inspired many novel approaches in materials research and nanochemistry, ${ }^{[115,116]}$ which are now sufficiently developed that as illustrated in this review, new concepts are being generated that have potential biological relevance. Thus, the translation from biomineral ization to biomimetics is no longer unidirectional but synergistic. We therefore expect that this increasing feedback loop will not only stimulate further research in the inorganic structures of life but also continue to drive our vision and imagination in laboratory studies on the chemistry of organized matter.

We thank Drs M. Li, L. M. Qi, and S. H. Yu for key experimental studies on the microemulsion based and poly mer based syntheses of organized nanostructures and arrays, and Prof. A. Bigi and E. Boanini for collaborative studies on the growth of complex calcium phosphate spheroids.

[1] P. Yang, A. H. Rizvi, B. Messer, B. F. Chmelka, G. M. White sides, G. D. Stucky, Adv. Mater. 2001, 13, 427431.

[2] W. Shenton, D. Pum, U. B. Sleytr, S. Mann, Nature 1997, 389, 585587.

[3] C. B. Murray, C. R. Kagan, M. G. Bawendi, Science 1995, 270, 13351338.

[4] Z. L. Wang, Adv. Mater. 1998, 10, 1330.

[5] R. P. Andres, J. D. Bielefeld, J. I. Henderson, D. B. Janes, V. R. Kolagunta, C. P. Kubiak, W. J. Mahoney, R. G. Osifchin, Science 1996, 273, 16901693.

[6] T. H. Galow, A. K. Boal, V. M. Rotello, Adv. Mater. 2000, 12, 576579.

[7] C. A. Mirkin, R. L. Letsinger, R. C. Mucic, J. J. Storhoff, Nature 1996, 382, 607609 .
[8] S. Mann, W. Shenton, M. Li, S. Connolly, D. Fitzmaurice, Adv. Mater. 2000, 12, 147150.

[9] E. Dujardin, L. B. Hsin, C. R. C. Wang, S. Mann, Chem. Commun. 2001, 12641265.

[10] S. Mann, Angew. Chem. 2000, 112, 3532 3548; Angew. Chem. Int. Ed. 2000, 39, 33923406.

[11] S. Mann, Biomimetic Materials Chemistry, VCH, New York, 1996.

[12] Biomimetics: Design and Processing of Materials (Eds.: M. Sarikaya, I. A. Aksay), AIP Press, Woodbury, NY, 1995 (American Institute of Physics Series in Polymers and Complex Materials).

[13] M. Yoshimura, W. Suchanek, K. Byrappa, MRS Bull. 2000, 9, 1725.

[14] S. H. Yu, J. Ceram. Soc. Jpn. 2001, 109, S65 S75.

[15] J. Rieger, E. Hädicke, I. U. Rau, D. Boeckh, Tenside Surfactants Deterg. 1997, 34, 430435.

[16] O. Söhnel, J. W. Mullin, J. Cryst. Growth 1982, 60, 239250.

[17] The classical theory of nucleation considers the spontaneous formation of spherical molecular clusters with size dependent free energies that continue to grow only when larger than the threshold value of the critical radius (D. H. Everett, Basic Principles of Colloid Science, The Royal Society of Chemistry, London, 1988; O. Söhnel, J. Garside Precipitation, Butterworth Heinemann, Oxford, 1992). The model predicts the size of the critical nucleus and associated activation energy and nucleation rate, as well as their dependence on supersaturation, but is severely limited by a number of assumptions and simplifica tions. In particular, the structure and composition of the nucleus is considered to be the same as the bulk crystalline phase and the formation of subcritical supramolecular clusters or complexes (H. Cölfen, H. Schnablegger, A. Fischer, F. C. Jentoft, G. Weinberg, R. Schlögl, Langmuir 2002, 18, 3500 3509) and multistep assembly of large unit cell structures are not addressed. Moreover, the experimental characterization of these transient solution species remains a major challenge, such that a quantitative/mechanistic analysis of nucleation is still to be developed.

[18] H. J. Arnott in, Mechanisms of Biomineralization in Animals and Plants (Eds.: M. Omori, N. Watabe), Tokai University Press, Tokyo, 1980.

[19] J. Aizenberg, G. Lambert, L. Addadi, S. Weiner, Adv. Mater. 1996, 8, 222226.

[20] J. Aizenberg, G. Lambert, S. Weiner, L. Addadi, J. Am. Chem. Soc. 2002, 124, 3239.

[21] M. G. Taylor, K. Simkiss, G. N. Greaves, M. Okazaki, S. Mann, Proc. R. Soc. London Ser. B 1993, 252, 7580.

[22] Y. Levi Kalisman, S. Raz, S. Weiner, L. Addadi, Adv. Funct. Mater. 2002, 12, 4348.

[23] B. Hasse, H. Ehrenberg, J. C. Marxen, W. Becker, M. Epple, Chem. Eur. J. 2000, 6, 36793685.

[24] S. Raz, S. Weiner, L. Addadi, Adv. Mater. 2000, 12, 3842.

[25] A. Ziegler, J. Struct. Biol. 1994, 112, 110116.

[26] E. Beniash, J. Aizenberg, L. Addadi, S. Weiner, Proc. R. Soc. London Ser. B 1997, 264, 461465.

[27] E. Beniash, L. Addadi, S. Weiner, J. Struct. Biol. 1999, 125, 50 62.

[28] A. Tsortos, S. Ohki, A. Zieba, R. E. Baier, G. H. Nancollas, J. Colloid Interface Sci. 1996, 177, 257262.

[29] S. Mann, D. D. Archibald, J. M. Didymus, T. Douglas, B. R. Heywood, F. C. Meldrum, N. J. Reeves, Science 1993, 261, 12861292.

[30] A. M. Belcher, X. H. Wu, R. J. Christensen, P. K. Hansma, G. D. Stucky, D. E. Morse, Nature 1996, 381, 5658.

[31] C. A. Orme, A. Noy, A. Wierzbicki, M. T. McBride, M. Grantham, H. H. Teng, P. M. Dove, J. J. DeYoreo, Nature 2001, 411, 775779 . 
[32] The classical model of crystal growth is based on surface solution interactions, which result in secondary nucleation, subjected to various conditions of rate limitation which include mass transport, polynucleation, layer by layer growth, screw dislocations. Growth is through the addition of soluble ions, molecules, ion pairs, and complexes to active sites on the existing crystal surface, such as kinks and steps. Various mechanistic equations have been derived: W. K. Burton, N. Cabrera, F. C. Frank, Philos. Trans. R. Soc. London Ser. A 1951, 243, 299358.

[33] N. Jongen, P. Bowen, J. Lemaître, J. C. Valmalette, H. Hofmann, J. Colloid Interface Sci. 2000, 226, 189198.

[34] R. L. Penn, J. F. Banfield, Geochim. Cosmochim. Acta 1999, 63, 15491557

[35] E. Matijevic, P. Sheiner, J. Colloid Interface Sci. 1978, 63, 509 524.

[36] W. P. Hsu, L. Ronnquist, E. Matijevic, Langmuir 1988, 4, 31 37.

[37] S. H. Lee, Y. S. Her, E. Matijevic, J. Colloid Interface Sci. 1997, 186, 193202.

[38] T. Sugimoto, Y. Wang, H. Itoh, A. Muramatsu, Colloids Surf. A 1998, 134, 265279.

[39] V. Privman, D. V. Goia, J. Park, E. Matijevic, J. Colloid Interface Sci. 1999, 213, 3645.

[40] M. Ocana, M. P. Morales, C. J. Serna, J. Colloid Interface Sci. 1995, 171, 85 91; M. Ocana, M. P. Morales, C. J. Serna, J. Colloid Interface Sci. 1999, 212, 317323.

[41] J. F. Banfield, S. A. Welch, H. Zhang, T. T. Ebert, R. L. Penn, Science 2000, 289, 751754.

[42] C. Pacholski, A. Kornowski, H. Weller, Angew. Chem. 2002 114, 1234 1237; Angew. Chem. Int. Ed. 2002, 41, 11881191.

[43] M. Yeadon, M. Ghaly, J. C. Yang, R. S. Averback, J. M. Gibson, Appl. Phys. Lett. 1998, 73, 32083210.

[44] D. M. Murphy Wilhelmy, E. Matijevic, J. Chem. Soc. Faraday Trans. 1 1984, 80, 536570.

[45] J. H. Adair, E. Suvaci, Curr. Opin. Colloid Interface Sci. 2000, 5 , 160167

[46] H. Cölfen, L. M. Qi, Y. Mastai, L. Börger, Cryst. Growth Des. 2002, 2, 191196.

[47] "The Stability of Solid/Liquid Dispersions in the Presence of Polymers": B. Vincent in Solid/Liquid Dispersions (Ed.: T. F. Tadros), Academic Press, London, 1987.

[48] G. J. Fleer, M. A. Cohen Stuart, J. M. H. Scheutjens, T. Cos grove, B. Vincent, Polymers at Interfaces, Chapman Hall, London, 1993.

[49] L. M. Qi, H. Cölfen, M. Antonietti, Angew. Chem. 2000, 112, 617 621; Angew. Chem. Int. Ed. 2000, 39, 604607.

[50] A. Taubert, D. Palms, Ö. Weiss, M. T. Piccini, D. N. Batchelder, Chem. Mater. 2002, 14, 25942601.

[51] G. Wegner, P. Baum, M. Müller, J. Norwig, K. Landfester, Macromol. Symp. 2001, 175, 349355.

[52] A. Berman, L. Addadi, S. Weiner, Nature 1988, 331, 546548.

[53] A. Berman, J. Hanson, L. Leiserowitz, T. F. Koetzle, S. Weiner, L. Addadi, Science 1993, 259, 776779.

[54] J. Aizenberg, J. Hanson, T. F. Koetzle, S. Weiner, L. Addadi, J. Am. Chem. Soc. 1997, 119, 881886.

[55] L. M. Qi, H. Cölfen, M. Antonietti, Chem. Mater. 2000, 12, 23922403

[56] H. Cölfen, L. M. Qi, Chem. Eur. J. 2001, 7, 106116.

[57] R. Kniep, S. Busch, Angew. Chem. 1996, 108, 2788 2791; Angew. Chem. Int. Ed. Engl. 1996, 35, 26242626.

[58] S. Busch, H. Dolhaine, A. DuChesne, S. Heinz, O. Hochrein, F. Laeri, O. Podebrad, U. Vietze, T. Weiland, R. Kniep, Eur. J. Inorg. Chem. 1999, 16431653.

[59] S. H. Yu, H. Cölfen, J. Hartmann, M. Antonietti, Adv. Funct. Mater. 2002, 12, 541545.

[60] H. Cölfen, M. Antonietti, Langmuir 1998, 14, 582589.
[61] H. Cölfen, Macromol. Rapid Commun. 2001, 22, 219252.

[62] L. M. Qi, J. Li, J. M. Ma, Chem. J. Chin. Univ. 2002, 23, 1595 1597.

[63] S. A. Davis, M. Breulmann, K. H. Rhodes, B. Zhang, S. Mann, Chem. Mater. 2001, 13, 32183226.

[64] S. Mann, S. A. Davis, S. R. Hall, M. Li, K. H. Rhodes, W. Shenton, S. Vaucher, B. Zhang, J. Chem. Soc. Dalton Trans. 2000, 37533763.

[65] X. Peng, L. Manna, W. Yang, J. Wickham, E. Scher, A. Kadavanich, A. P. Alivisatos, Nature 2000, 404, 5961.

[66] M. Brust, D. Bethell, D. J. Schiffrin, C. J. Kiely, Adv. Mater. 1995, 7, 795797

[67] M. Li, H. Schnablegger, S. Mann, Nature 1999, 402, 393395.

[68] B. Nikoobakht, Z. L. Wang, M. A. El Sayed, J. Phys. Chem. B 2000, 104, 86358640.

[69] V. F. Puntes, K. M. Krishnan, A. P. Alivisatos, Science 2001, 291, 21152117.

[70] N. R. Jana, L. A. Gearheart, S. O. Obare, C. J. Johnson, K. E. Edler, S. Mann, C. J. Murphy, J. Mater. Chem., 2002, 12, 2909 2912.

[71] C. A. Mirkin, R. L. Letsinger, R. C. Mucic, J. J. Storhoff, Nature 1996, 382, 607609 .

[72] A. P. Alivisatos, K. P. Johnsson, X. G. Peng, T. E. Wilson, C. J. Loweth, M. P. Bruchez, P. G. Schulz, Nature 1996, 382, 609 611.

[73] E. H. Tadd, J. Bradley, R. Tannenbaum, Langmuir 2002, 18, 23782384.

[74] J. P. Spatz, S. Mössmer, C. Hartmann, M. Möller, T. Herzog, M. Krieger, H. G. Boyen, P. Ziemann, B. Kabius, Langmuir 2000, 16, 407415.

[75] Y. Boontongkong, R. E. Cohen, Macromolecules 2002, 35 , 36473652.

[76] W. A. Lopes, H. M. Jaeger, Nature 2001, 414, 735738.

[77] C. G. Göltner, S. Henke, M. C. Weissenberger, M. Antonietti, Angew. Chem. 1998, 110, 633 636; Angew. Chem. Int. Ed. 1998, 37, 613616.

[78] D. Zhao, W. Huo, J. Feng, B. F. Chmelka, G. D. Stucky, J. Am. Chem. Soc. 1998, 120, 60246036.

[79] Many conventional surfactants have also been used to prepare mesoporous silicas, for example, C. T. Kresge, M. E. Leono wicz, W. J. Roth, J. C. Vartuli, J. S. Beck, Nature 1992, 359, 710 712.

[80] M. Sumper, Science 2002, 295, 24302433.

[81] E. G. Vrieling, T. P. M. Beelen, R. A. van Santen, W. C. Gieskes, Angew. Chem. 2002, 114, 1613 1616; Angew. Chem. Int. Ed. 2002, 41, 15431546.

[82] M. Li, S. Mann, Langmuir 2000, 16, 70887094.

[83] L. M. Qi, J. Ma, H. Cheng, Z. Zhao, J. Phys. Chem. B 1997, 101, 34603463.

[84] G. D. Rees, R. Evans Gowing, S. J. Hammond, B. H. Robinson, Langmuir 1999, 15, 19932002.

[85] M. Li, S. Mann, Adv. Functional Mater., 2002, 12, 773779.

[86] L. M. Qi, H. Cölfen, M. Antonietti, M. Li, J. D. Hopwood, A. J. Ashley, S. Mann, Chem. Eur. J. 2001, 7, 35263532.

[87] S. H. Yu, M. Antonietti, H. Cölfen, Nano Lett., 2003, 3, 379 382.

[88] S. H. Yu, H. Cölfen, M. Antonietti, Chem. Eur. J. 2002, 8, 2937 2945.

[89] M. Antonietti, M. Breulmann, C. G. Göltner, H. Cölfen, K. K. W. Wong, D. Walsh, S. Mann, Chem. Eur. J. 1998, 4, 24912500.

[90] A. Peytcheva, H. Cölfen, H. Schnablegger, M. Antonietti, Colloid Polym. Sci. 2002, 280, 218227.

[91] D. B. Zhang, L. M. Qi, J. M. Ma, H. M. Cheng, Chem. Mater. 2001, 13, 27532755.

[92] L. B. Gower, D. A. Tirrell, J. Cryst. Growth 1998, 191, 153160.

[93] L. B. Gower, D. J. Odom, J. Cryst. Growth 2000, 210, 719734. 
[94] A. Bigi, E. Boanini, D. Walsh, S. Mann, Angew. Chem. 2002, 114, 2267 2270; Angew. Chem. Int. Ed. 2002, 41, 21632166.

[95] H. A. Lowenstam, S. Weiner, On Biomineralization, Oxford University Press, New York, 1989, pp. 207251.

[96] E. Bäuerlein, Biomineralization: From Biology to Biotechnol ogy and Medical Application, Wiley VCH, Weinheim, 2000.

[97] S. Mann, Biomineralization. Principles and Concepts in Bio inorganic Materials Chemistry, Oxford University Press, Oxford, 2001.

[98] H. A. Lowenstam, Science 1981, 211, 11261131.

[99] S. Mann, Nature 1988, 332, 119124.

[100] S. Weiner, W. Traub, Philos. Trans. R. Soc. London Ser. B 1984, 304, 425434.

[101] L. Addadi, S. Weiner, Proc. Natl. Acad. Sci. USA 1985, 82, 41104114

[102] M. E. Marsh, D. P. Dickinson, Protoplasma 1997, 199, 917.

[103] T. Samata, N. Hayashi, M. Kono, K. Hasegawa, C. Horita, S. Akera, FEBS Lett. 1999, 462, 225229.

[104] X. Shen, A. M. Belcher, P. K. Hansma, G. D. Stucky, D. E. Morse, J. Biol. Chem. 1997, 272, 3247232481.

[105] J. D. Termine, Rheumatology 1986, 10, 499509.

[106] M. E. Marsh, Protoplasma 1994, 177, 108122.

[107] M. E. Marsh, Biochemistry 1989, 28, 339345.

[108] M. E. Marsh, R. L. Sass, J. Exp. Zool. 1985, 234, 237242.

[109] C. S. Sikes, A. P. Wheeler, A. Wierzbicki, R. M. Dillaman, L. De Luca, Biol. Bull. 1998, 194, 304316.

[110] "Dental Enamel": A. G. Fincham, J. P. Simmer, Ciba Found. Symp. 1997, 205, 118134

[111] L. W. Fischer in The Chemistry and Biology of Mineralized Tissues (Ed.: W. T. Butler), EBSCO Media, Birmingham, AL, 1985, pp. 188195.

[112] J. Webb, D. J. Macey, S. Mann in Biomineralization: Chemical and Biochemical Perspectives (Ed.: S. Mann, J. Webb, R. J. P. Williams), VCH, Weinheim, 1989, pp. 345438.

[113] G. J. A. A. Soler Illia, C. Sanchez, B. Lebeau, J. Paterin, Chem. Rev. 2002, 102, 4093.

[114] C. Sanchez, G. J. A. A. Soler Illia, F. Ribot, C. Mayer, V. Cabuil, T. Lalot, Chem. Mater. 2001, 13, 3061.

[115] The loose translation of biomineralization concepts has inspired the synthesis with construction of organized nano structures, oriented crystal arrays, microarchitectures with complex form, and hierarchical materials with structure and form extending across many length scales (A. H. Heuer, D. J. Fink, V. J. Laraia, J. L. Arias, P. D. Calvert, K. Kendall, G. L. Messing, J. Blackwell, P. C. Rieke, D. H. Thompson, A. P. Wheeler, A. Veis, A. I. Caplan, Science 1992, 255, 1098 1105; S. Mann, G. A. Ozin, Nature 1996, 382, 313 318; S. Mann, Nature 1993, 365, 499 505; S. Mann, S. L. Burkett, S. A. Davis, C. E. Fowler, N. H. Mendelson, S. D. Sims, D. Walsh, N. T. Whilton, Chem. Mater. 1997, 9, 2300 2310).

[116] Potential spin offs from biomineral inspired research include; a) oriented nucleation of inorganic crystals and thin films using functionalied organic surfaces ((B. R. Heywood, S. Mann, Adv. Mater. 1994, 6, 9 20; I. A. Aksay, M. Trau, S. Manne, I. Honma, N. Yao, L. Zhou, P. Fenter, P. M. Eisenberger, S. M. Gruner, Science 1996, 273, 892 898; J. Yang, F. C. Meldrum, J. H. Fendler, J. Phys. Chem. 1995, 99, 5500 5504; J. Aizenberg, A. J. Black, G. M. Whitesides, Nature 1999, 398, 495 498), b) use of bioorganic supramolecular structures, such as vesicles and lipid tubules, to direct the nucleation and growth of shaped inorganic materials (D. D. Archibald, S. Mann, Nature 1993, 364, 430 433; P. T. Tanev, T. J. Pinnavaia, Science 1996, 271, 1267 1269; J. D. Hartgerink, E. Beniash, S. I. Stupp, Science 2001, 294, 1684 1688; A. M. Seddon, H. M. Patel, S. L. Burkett, S. Mann, Angew. Chem. 2002, 114, 3114 3117; Angew. Chem. Int. Ed. 2002, 41, 2988 2991), c) new developments in the design of additives, such as block copolymers and dendrimers for control of crystal habit (ref. [57] and H. Cölfen, L. M. Qi, Chem. Eur. J. 2001, 7, 106 116; H. Cölfen, M. Antonietti, Langmuir 1998, 14, 582589 ; J. J. J. M. Donners, B. R. Heywood, E. W. Meijer, R. J. M. Nolte, C. Roman, A. P. H. J. Schenning, N. A. J. M. Sommerdijk, Chem. Commun. 2000, 1937 1938; K. Naka, Y. Tanaka, Y. Chujo, Y. Ito, Chem. Commun. 1999, 1931 1932; J. M. Marentette, J. Norwig, E. Stockelmann, W. H. Meyer, G. Wegner, Adv. Mater. 1997, 9, 647 651; K. L. Robinson, J. W. V. M. Weaver, S. P. Armes, E. D. Marti, F. C. Meldrum, J. Mater. Chem. 2002, 12, 890 896), and d) developments in the laboratory synthesis of inorganic materials with complex form by using organized reaction systems (D. Walsh, S. Mann, Nature 1995, 377, 320 323; D. Walsh, J. D. Hopwood, S. Mann, Science 1994, 264, 1576 1578; D. Walsh, B. Lebeau, S. Mann, $A d v$. Mater 1999, 11, 324 328; T. Hirai, S. Hariguchi, I. Komasawa, R. J. Davey, Langmuir 1997, 13, 6650 6653; L. B. Gower, D. A. Tirrell, J. Cryst. Growth 1998, 191, 153 160). 